
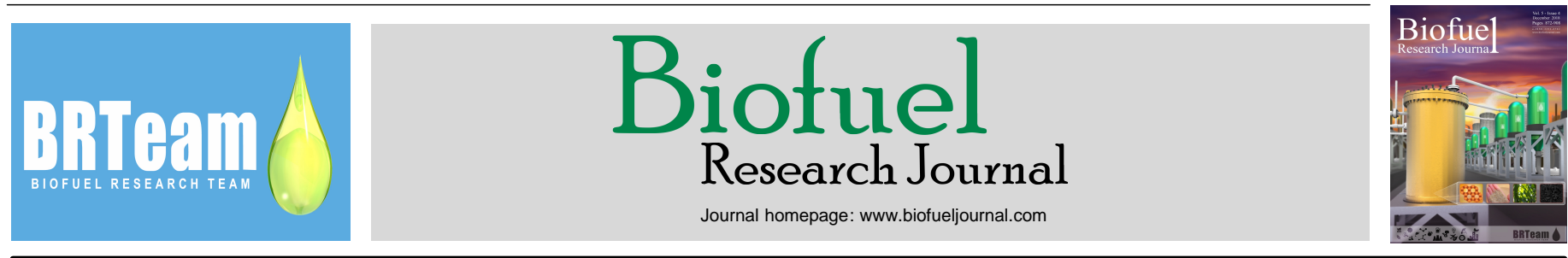

Review Paper

\title{
An overview of catalysts in biomass pyrolysis for production of biofuels
}

\author{
Ali $\operatorname{Imran}^{1,2, *, \dagger}$ Eddy A. Bramer ${ }^{1}$, K. Seshan ${ }^{2}$, Gerrit Brem ${ }^{1}$ \\ ${ }^{1}$ Laboratory of Thermal Engineering, Faculty of Engineering, University of Twente, PO Box 217, 7500 AE Enschede, The Netherlands. \\ ${ }^{2}$ Catalytic Processes and Materials, Faculty of Science \& Technology, University of Twente, PO Box 217, 7500 AE Enschede, The Netherlands.
}

\section{HIGHLIGHTS}

$>$ Performance of widely used catalysts for online catalytic upgrading of bio-oil is systematically reviewed and compared with respect to the scale of application, i.e., analytical, bench, and pilot scale.

$>$ Criteria for selection of catalyst for production of bio-oil have been comprehensively outlined. $>$ Effect of catalysts on chemical composition of bio-oil is reviewed and discussed in detail.

$>$ Demonstration scale FCC type process appears to have potentialsfor scale up for commercial production.

\section{GRAPHICAL ABSTRACT}

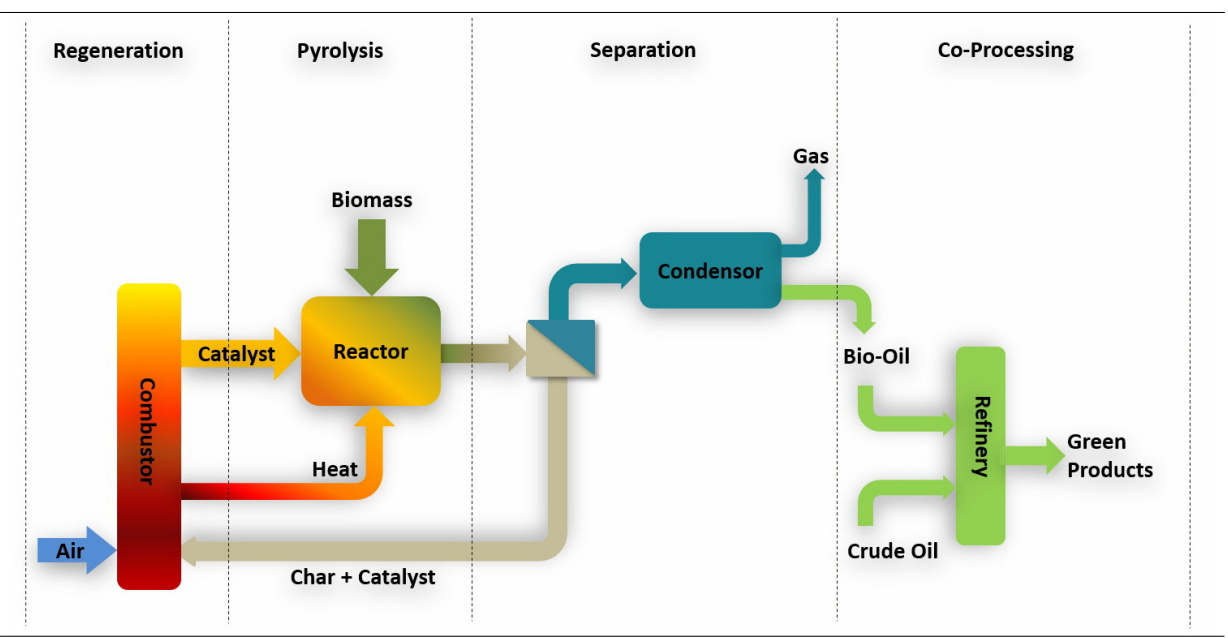

\section{ARTICLE INFO}

\begin{abstract}
In-situ catalytic pyrolysis of biomass has been extensively studied in recent years for cost-competitive production of high quality bio-oil. To achieve that, numerous catalysts have been studied to facilitate in-situ upgrading of low-grade condensable vapors (bio-oil) by converting oxygenated compounds and large-molecule species. In this review, these catalysts are categorized in different families and a systematic evaluation of the catalyst effects on pyrolysis products and their characteristics is carried out with respect to the scale of the experimental setup. Among these catalysts, microporous zeolites are considered as most promising in terms of performance and the potential to tailor the desired bio-oil properties. More specifically, the prominent advantages of zeolites include efficient deoxygenation and molecular weight reduction of the resultant bio-oil, while the main drawbacks are decreases in the yield of bio-oil's organic phase and catalyst deactivation by coke deposition. In addition to the zeolite-based catalysts, other catalysts including mesoporous aluminosilicates, a widely-applied class of catalysts used for deoxygenation of bio-oil as well as alkaline compounds are also reviewed and discussed herein. The research on the latter has not been extensive but the preliminary results have revealed their potential for deoxygenation of bio-oil, production of hydrocarbons, and reduction of undesired compounds. Nevertheless, these catalysts need to be further investigated systematically. Overall, further development of dedicated catalysts for selective deoxygenation and cracking of bio-oil would be essential for scaling up the existing pyrolysis technologies to achieve commercial production of biofuels through pyrolysis.
\end{abstract}

\section{Article history:}

Received 7 October 2018

Received in revised form 13 November 2018

Accepted 14 November 2018

Available online 1 December 2018

\section{Keywords:}

Catalytic pyrolysis

Biomass

Bio-oil

Biofuel

Catalyst

Deoxygenation

(C) 2018 BRTeam. All rights reserved.

* Corresponding author at: Tel.: +966 28082221

E-mail address: a.aliimran@utwente.nl ; ali.imran@kaust.edu.sa

$\dagger$ Present address: King Abdullah University of Science \& Technology, Thuwal 23955-6900, Saudi Arabia.

Please cite this article as: Imran A., Bramer E.A., Seshan K., Brem G. An overview of catalysts in biomass pyrolysis for production of biofuels. Biofuel Research Journal 20 (2018) 872-885. DOI: 10.18331/BRJ2018.5.4.2 


\section{Contents}

1. Introduction.

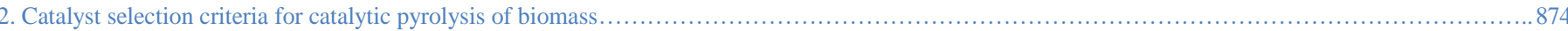

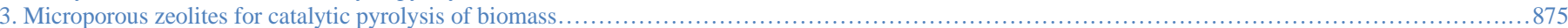

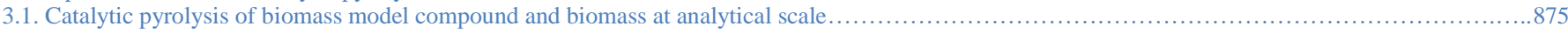

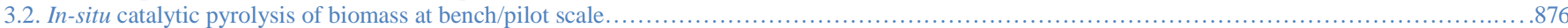

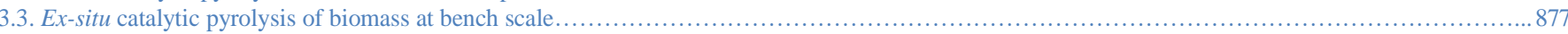

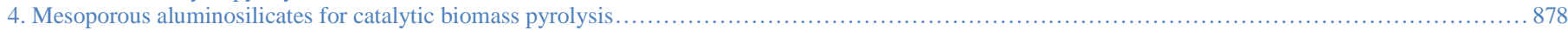

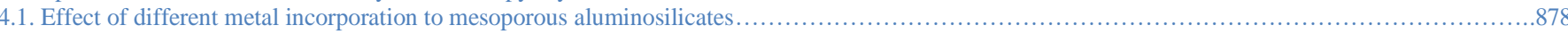

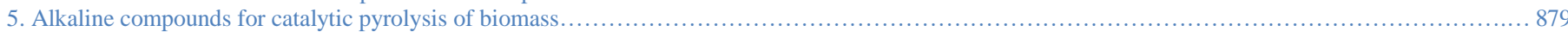

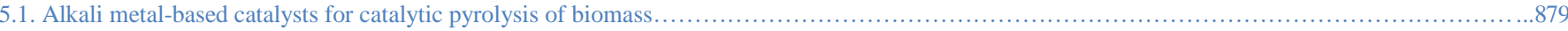

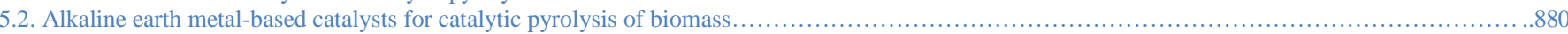

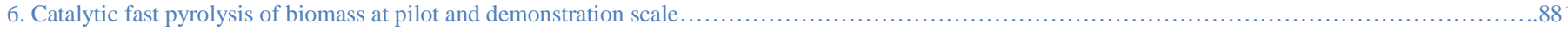

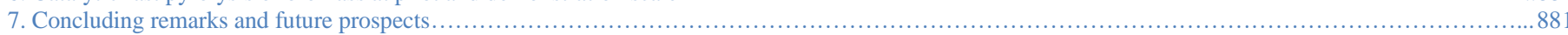

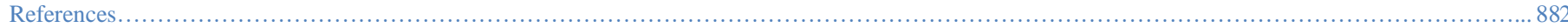

\section{Introduction}

Pyrolysis oil (i.e., bio-oil) can be produced by fast pyrolysis of biomass. Fast pyrolysis is a thermal oxygen-limited conversion involving a rapid heating (more than $1000{ }^{\circ} \mathrm{C} / \mathrm{s}$ ) of biomass at moderate temperatures of $400-600{ }^{\circ} \mathrm{C}$ in short time periods of $1-5 \mathrm{~s}$, producing condensable vapors, gases, and biochar. During a cooling process, the vapor compounds are subsequently condensed to form a liquid mixture also known as "bio-oil". It has been reported that the liquid yields can be as high as 70-75 wt.\% (incl. water) for wood. The bio-oil has some advantages over parent biomass including its higher energy density, favourable storage and transportation properties, and a relatively clean and homogeneous feedstock. Bio-oil has been used successfully for different applications such as gasifier feedstock, for use in diesel engines, and for cofeeding in boilers (Sturzl, 1997; Henrich et al., 2007; Van de Beld et al., 2013). Extensive reviews on the research conducted, technologies developed, and the application of biomass fast pyrolysis have been published previously (Bridgwater et al., 1999; Czernik and Bridgwater, 2004; Bridgwater, 2012; Jahirul et al., 2012).

Despite the advantages mentioned above, bio-oil is also characterized as acidic, corrosive, thermally unstable, polar, and highly oxygenated (Katikaneni et al., 1995; Bridgwater and Peacocke, 2000; Bridgwater, 2003; Yaman, 2004). In addition to those, bio-oil is also associated with more critical drawbacks including, its low heating value which is approximately $40-50 \%$ lower than that of fuel oil, its high viscosity, its substantial solids content, and its high water content of $25-30 \mathrm{wt} . \%$. This water cannot be readily separated, making bio-oil immiscible with conventional fuels (Bridgwater, 2003). Therefore, the bio-oil produced with conventional technologies is not suitable for direct use as a transportation fuel or as a fuel additive (Bridgwater, 2012). The oxygen content of bio-oil ranges from 30-55 wt.\% depending upon the parent biomass (Czernik and Bridgwater, 2004). The oxygenated compounds in bio-oil, originating mainly from the principal constituents of biomass (i.e., cellulose, hemicellulose, and lignin), have major contribution to most of its deleterious properties.

As an example, Table 1 compares the different properties of the bio-oil generated through wood pyrolysis and heavy fuel oil. As shown, the generate bio-oil has a comparatively higher oxygen content and lower $\mathrm{H} / \mathrm{C}$ ratio (Oasmaa and Czernik, 1999). High acidity is also one of the most problematic properties of bio-oil in general and for fuel applications in particular as it leads to the corrosion of materials involved. Acetic acid is the main organic acid present in bio-oil in large quantities (at concentrations of $\sim 5 \mathrm{wt} . \%$ ) followed by formic acids ( $3 \mathrm{wt} . \%)$ (Piskorz et al., 1988). In fact, these acidic and carbonyl compounds present in bio-oil are responsible for both its low $\mathrm{pH}$ value and low calorific value. Another crucial problematic property of bio-oil is its thermal or storage stability, influencing the viscosity and molecular weight of bio-oil over time. It should be noted that viscosity is an essential issue especially for applications where pumping and injecting of bio-oil are involved. Carbonyl compounds such as aldehydes and ketones play a key role in the aging reactions because these reactive oxygenates tend to repolymerize into oligomers over time leading to chemical instability of bio-oil. Moreover, viscosity of bio-oil correlates with its molecular weight, hence, large concentrations of heavy components (molecular weight $>1000 \mathrm{~g} / \mathrm{mol}$ ) are responsible for the instability and high viscosity of bio-oil and can subsequently cause many problems in
Table 1.

Typical properties of wood pyrolysis bio-oil and heavy fuel oil (Oasmaa and Czernik, 1999).

\begin{tabular}{lcc}
\hline Physical property & Bio-oil & Heavy fuel oil \\
\hline Moisture content (wt.\%) & $15-30$ & 0.1 \\
$\mathrm{pH}$ & 2.5 & - \\
Specific gravity & 1.2 & 0.94 \\
$\mathrm{C}$ & $54-58$ & 85 \\
$\mathrm{H}$ & $5.5-7.0$ & 11 \\
$\mathrm{O}$ & $35-40$ & 1.0 \\
$\mathrm{~N}$ & $0-0.2$ & 0.3 \\
Ash & $0-0.2$ & 0.1 \\
HHV, MJ/kg & $16-19$ & 40 \\
Viscosity $\left(\right.$ at $\left.50{ }^{\circ} \mathrm{C}\right), \mathrm{cP}$ & $40-100$ & 180 \\
Solids (wt.\%) & $0.2-1$ & 1 \\
Distillation residue (wt.\%) & Up to 50 & 1 \\
\hline
\end{tabular}

downstream conversion units (Scholze et al., 2001; Oasmaa and Kuoppala, 2003). Most of these heavy components are lignin derivatives (Bridgwater 1994). In this regard, the viscosity and stability of bio-oil can be improved by cracking these large molecules into favorable lower molecular weight compounds.

Overall, in order to improve the quality of bio-oil, the oxygenated compounds and the lignin-derived large molecules need to be removed or reformed into components that are more useful. There are several options for upgrading and improving bio-oil quality. One method is the conversion of biomass into bio-oil and then, upgrading the bio-oil over a catalyst, for example via hydrodeoxygenation (HDO) and zeolite cracking. Post pyrolysis catalytic upgrading of bio-oil, also known as ex-situ process, has been extensively reviewed (Maggi and Delmon, 1994; Elliott, 2007; Mortensen et al., 2011) but has not been found very promising. More specifically, catalytic after-treatment process suffers from fast deactivation of the catalyst caused by coking and poor yield of hydrocarbons due to bypassing of the larger molecular species contained in bio-oil (Oasmaa and Kuoppala, 2003). Comparatively, although HDO appears to hold higher potentials against zeolite cracking, but there exist several concerns associated with this approach, which should be addressed before its commercialization. Those include development of more efficient catalysts and providing more sustainable sources of hydrogen.

Another approach to upgrade bio-oil would be the in-situ catalytic pyrolysis involving on-site treatment of pyrolysis vapours prior to the condensation step. The in-situ and ex-situ processes are presented in Figure 1. The in-situ catalytic pyrolysis is capable of inducing the cracking reactions to break down the heavy molecules present in the pyrolysis products leading to the formation of lighter and less viscous bio-oils containing a larger proportion of high-value compounds such as hydrocarbons and phenols.

In-situ catalytic treatment of bio-oil vapours could be carried out in the same pyrolysis reactor, e.g., a fluidized bed reactor while the ex-situ route 
can be performed at the downstream of the pyrolysis reactor in a separate reactor, e.g., a packed bed reactor system. Both options have the advantage of adopting the existing pyrolysis reactor systems; the former option requires lower capital investment and offers better technical benefits though. The performance of the catalysts used in different modes of pyrolysis, i.e., in-situ and ex-situ, and with respect to the scale of the experimental setup, i.e., analytical scale, bench scale, and pilot scale, are reviewed and discussed herein.

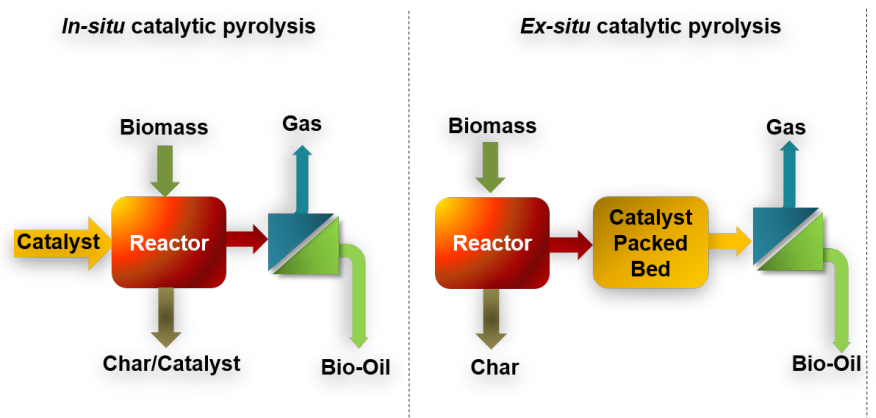

Fig. 1. Two process schemes for online catalytic pyrolysis reaction pathway for conversion of bio-oil over zeolite catalysts.

\section{Catalyst selection criteria for catalytic pyrolysis of biomass}

A wide range of organic compounds is found in the bio-oil produced via fast pyrolysis of biomass. The identified compounds of organic phase are typically categorized into hydrocarbons, phenols, furans, acids, alcohols, aldehydes, esters, ketones, aromatics, polycyclic aromatic hydrocarbons (PAHs), and heavy compounds. In Table 2, the chemical composition of the bio-oil derived from maple wood is tabulated in which the compounds are classified according to their chemical nature and identified as desired, undesired, and valuable compounds (Adjaye and Bakhshi, 1995).

Table 2.

Composition of maple wood-derived bio-oil (Adjaye and Bakhshi, 1995).

\begin{tabular}{lcc}
\hline & Amount (Wt.\%) & Remark \\
\hline Aliphatic hydrocarbons & & \\
Alkanes & & \\
Alkenes & 0.5 & Desired \\
Cyclic hydrocarbons & & \\
Aromatic hydrocarbons & & \\
Monoaromatic compounds & 5.6 & Desired \\
Polycyclic aromatic hydrocarbons & & Undesired \\
& & \\
Oxygenated compounds & 10.9 & Undesired \\
Aldehydes & 36.6 & Undesired \\
Ketones & 10.4 & Undesired \\
Carboxylic acids and Esters & 2.5 & Valuable \\
Furans & 2.2 & - \\
Ethers & 5.3 & Valuable \\
Alcohols & 10.9 & Valuable \\
Phenols & 14.7 & - \\
Unidentified & & \\
\hline
\end{tabular}

Hydrocarbons are a desirable fraction for fuel applications while compounds like phenol and its alkylated derivatives have high commercial values especially for resin or adhesive industry, making the process economically attractive. On the contrary, oxygen-containing compounds, such as acids and carbonyls as well as heavy compounds are considered as undesirable fractions. The reduction of acids is important to address the corrosiveness of the bio-oil while the reduction of carbonyls and heavy compounds is important to improve the stability and storage properties of the product. Reduction of PAHs is also desirable, since they are considered as persistent species that are hazardous to the health and the environment. Furans are considered valuable because of their fuel compatibility and high-energy value. In order to improve the quality of bio-oil as transportation fuel, development of promising catalysts producing more of the desirable and less of the undesirable fractions would be essential.

The challenge in catalyst development is to design a deoxygenating catalyst capable of selectively removing problematic oxygenates present in bio-oil and thus, in one step improving the physical properties of bio-oil. Oxygen could be removed by different reactions, i.e., dehydration, decarbonylation, and decarboxylation leading to the generation of water, $\mathrm{CO}$, and $\mathrm{CO}_{2}$, respectively. Selective removal of oxygen by decarboxylation of carboxylic acids (formic, acetic acids) could decrease the acidity of bio-oil while selective decarbonylation of organic fractions (aldehydes, unsaturated species, etc.) could contribute to improved stabilization of the oil. The best mode of deoxygenation of the vapors is determined through carrying out calorific value calculations considering the elemental formula $\left(\mathrm{C}_{6} \mathrm{H}_{8} \mathrm{O}_{4}\right)$ of bio-oil (Fig. 2). As shown, 75\% deoxygenation via decarboxylation could improve the higher heating value (HHV) of bio-oil from $19.4 \mathrm{MJ} / \mathrm{kg}$ to 34.1 $\mathrm{MJ} / \mathrm{kg}$. It is evident from these calculations that the decarboxylation is the preferred route for deoxygenation in comparison with dehydration and decarbonylation as decarboxylation allows the retention of hydrogen in biooil, maximizes oxygen removal with minimal carbon loss, and thereby, increases heating value, decreases the aromatics formation, minimizes water content, and decreases hydrophilicity.

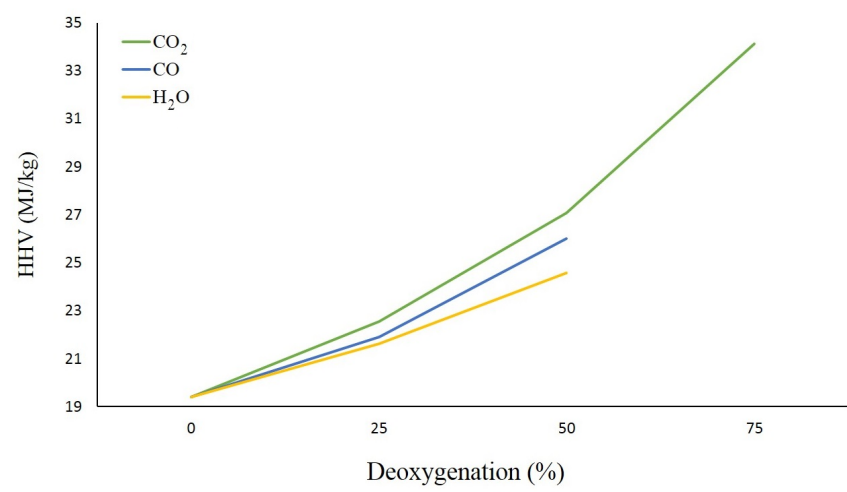

Fig. 2. Effectiveness of different deoxygenation processes in improving the heating value of the bio-oil.

Apart from unfavorable oxygenated compounds, bio-oil also contains large molecules derived from lignin. Appropriate catalysts should be able to selectively crack these compounds in the pyrolysis products. Since the heavy lignin derivatives also contain a high proportion of oxygen, reducing these compounds and simultaneously increasing hydrocarbons yields would decrease the oxygen content of bio-oil and increase its heating value. It should be noted that catalytic cracking is a well-known process in petroleum refineries and is used to break down the large and complex hydrocarbon molecules into smaller and simpler ones. The catalytic cracking of hydrocarbons is believed to be a chain reaction that follows the carbenium ion theory developed by Whitmore (1934), and the mechanism includes three steps: initiation, propagation, and cracking (Watson et al., 1997). In the cracking of hydrocarbons, the main reaction routes involve $\mathrm{C}-\mathrm{C}$ bond scission (Wojciechowski and Corma, 1986) while in the case of biomass pyrolysis, the cleavage of $\mathrm{C}-\mathrm{OH}$ bonds (dehydration) and $\mathrm{C}-$ $\mathrm{CO}(\mathrm{OH})$ bonds (decarbonylation or decarboxylation) also take place. Thus, a catalyst for biomass pyrolysis should be capable of simultaneously catalyzing several reactions including dehydration, decarboxylation, decarbonylation, (de)alkylation, cracking, isomerization, cyclization, oligomerization, and aromatization. 
Different types of catalysts have been studied for both in-situ and ex-situ catalytic pyrolysis of biomass, such as zeolites (ZSM-5, Y, Mordenite, and Beta), silica-alumina, activated alumina, mesoporous aluminosilicates, alkali metals, and alkaline earth metals. The specific catalytic function of various catalysts can alter product yields and selectivity, thus affecting the composition of bio-oil and its physical and chemical properties. For instance, Adjaye and Bakhshi (1995) proposed different reaction pathways for conversion of bio-oil in the presence of zeolite and silica-alumina catalysts (Fig. 3). As presented, the zeolite-based catalysts tented to produce $\mathrm{C} 2-\mathrm{C} 6$ olefins, while the silicaalumina favored to generation of $\mathrm{C} 2-\mathrm{C} 9$ olefins in the resultant bio-oils.

In the subsequent sections, the application of zeolite-based catalysts, aluminosilicates, and alkaline compounds for catalytic pyrolysis of biomass are reviewed and discussed.
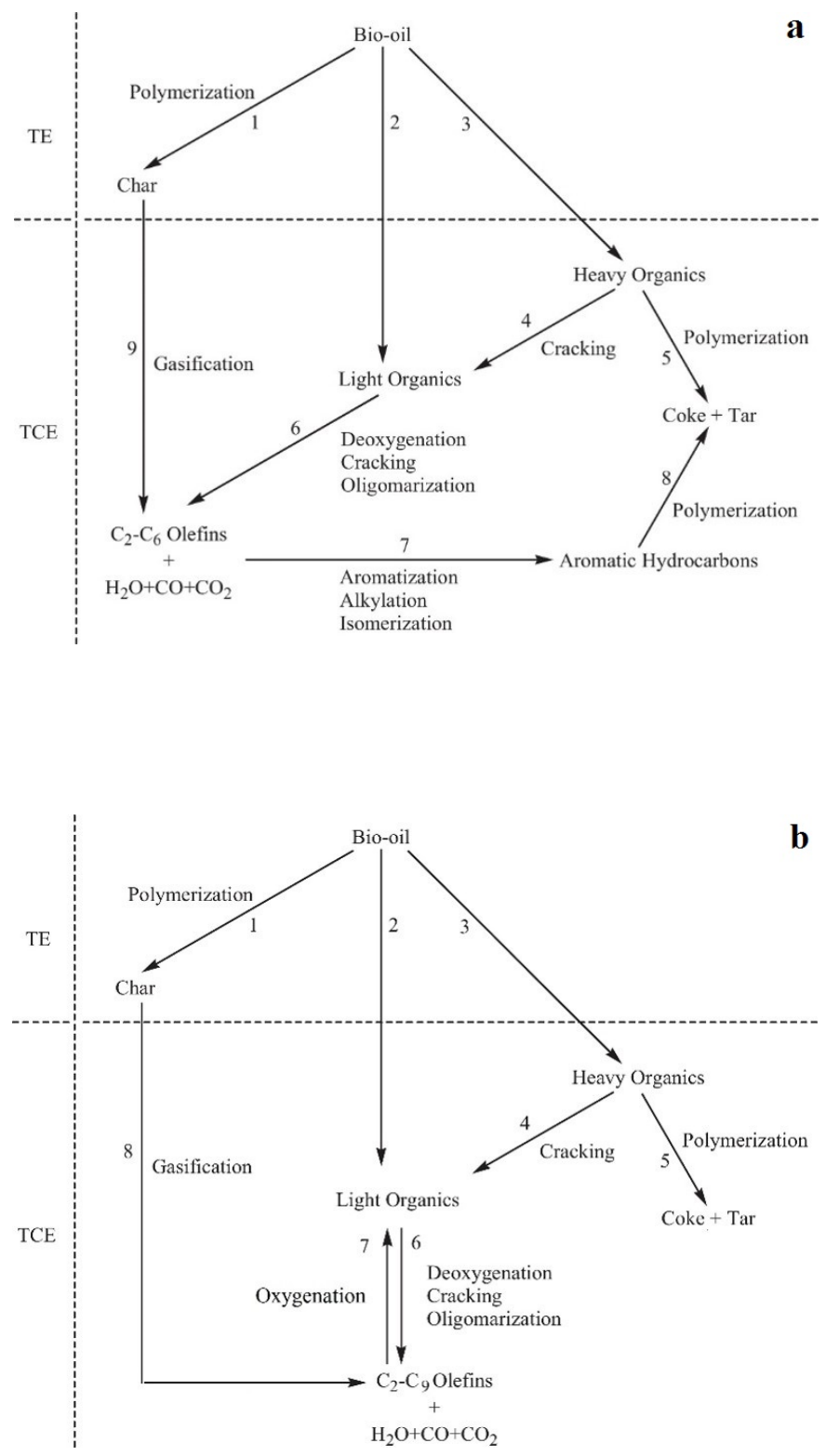

Fig. 3. Reaction pathway for conversion of bio-oil over (a) zeolite and (b) silica-alumina catalysts (TE: thermal effect; TCE: thermo-catalytic effect).

\section{Microporous zeolites for catalytic pyrolysis of biomass}

3.1. Catalytic pyrolysis of biomass model compound and biomass at analytical scale

Zeolites are typical catalysts used in the petroleum industry for upgrading low-octane components in the gasoline boiling range, as well as for isomerizing low-octane linear olefins to high-octane branched olefins (Sadeghbeigi, 2000). The advantages of applying zeolites for biomass pyrolysis are attributed to their relatively low price and the knowledge gained over decades from their applications in chemical industries. Zeolites represent a well-defined class of crystalline aluminosilicate minerals whose three-dimensional structures are derived from coordination polyhedral of $[\mathrm{SiO} 4]^{4-}$ and $[\mathrm{AlO} 4]^{5-}$ (Bhatia, 1989). The critical properties of zeolites are their structure, $\mathrm{Si} / \mathrm{Al}$ ratio, particle size, and nature of the (exchanged) cation. These primary structure/composition factors influence its acidity, thermal stability, and overall catalytic activity. The acidic properties (Brønsted sites) of zeolites are dependent on the method of preparation, the form and the temperature of dehydration, and the $\mathrm{Si} / \mathrm{Al}$ ratio. The structures of common zeolites are tabulated in Table 3 (Kirk-Othmer, 2007).

Table 3.

Channel structures of common zeolites (Kirk-Othmer, 2007).

\begin{tabular}{|c|c|}
\hline Zeolites & Channel structure \\
\hline ZSM-5 & $\begin{array}{l}\text { 3-Dimensional pore system; straight } 10 \text { member-ring } 5.2 \times 5.7 \AA \\
\text { channels connected by sinusoidal } 5.3 \times 5.6 \AA \text { channels. } \\
\text { Intersection cavity: } 9 \AA\end{array}$ \\
\hline Mordenite & $\begin{array}{l}\text { 2-Dimensional pore system; straight } 12 \text {-ring } 7.0 \times 6.5 \AA \text { channels } \\
\text { connected by short alternating 8-ring channels }(3 \AA \text { ) }\end{array}$ \\
\hline Beta & $\begin{array}{l}\text { 3-Dimensional pore system; } 12 \text {-ring channel in c direction with } \\
\text { pores } 7.6 \times 6.4 \AA \text { plus two } 12 \text {-ring channels in a direction } \\
\text { perpendicular to c-direction with pores } 7.6 \times 6.4 \AA \text { and } 5.5 \times 5.5 \AA\end{array}$ \\
\hline $\mathrm{Y}$ & $\begin{array}{l}\text { 3-Dimensional pore structure; circular } 12 \text { member-ring } 7.4 \AA \\
\text { windows connecting spherical } 11.8 \AA \text { cavities (super cages) }\end{array}$ \\
\hline
\end{tabular}

Among different zeolite-based catalysts, ZSM-5 is considered to be an effective catalyst for cracking, deoxygenation, and formation of aromatic hydrocarbons (Wojciechowski and Corma, 1986; Horne and Williams, 1994; Williams and Horne, 1994; Horne et al., 1995; Williams and Horne, 1995a; Horne and Williams, 1996; Samolada et al., 2000; Williams and Nugranad, 2000; Gayubo et al., 2004a). ZSM-5 was initially developed for the conversion of methanol and light alcohols to gasoline in wellrecognized methanol-to-gasoline (MTG) process. Promising catalytic performance of ZSM-5 is due to its unique shape selectivity. Hoff et al (2016) investigated the effect of the physicochemical properties of ZSM-5 catalyst on the yield of aromatic compounds produced by fast pyrolysis of cellulose. They found that aromatics formation was strongly dependent on the crystallinity and accessibility of framework aluminum sites.

It is worth mentioning that ZSM-5 has also been extensively studied for catalytic deoxygenation of oxygenated organic compounds (Chang and Hegedus, 1979; Dao et al., 1988). For example, transformation of alcohols, phenols, aldehydes, ketones, and acids, as the prominent components of bio-oil, was investigated over an HZSM-5 zeolite by Gayubo et al. (2004a and b) and these model compounds were shown to be significantly different in terms of reactivity and coke formation. In the continuation of this work, Gayubo et al. (2005) treated a mixture of acetone, acetic acid, acetaldehyde, phenol, 2-butanol, and methanol over HZSM-5, and obtained a high proportion of olefins, butenes, propene, aromatics, and paraffins. While a mixture of oxygenates containing 2-methoxyphenol and furfural showed low reactivity in the presence of HZSM-5 which could be ascribed to the formation of carbonaceous residues on the catalyst. They also argued that, aldehydes, phenols, and furfural could undergo severe thermal degradation resulting in the formation of carbonaceous deposits on the catalyst, and consequently, an intense deactivation of the catalyst.

Carlson et al. (2008 and 2009) also evaluated different zeolite-based catalysts in a pyroprobe analytical pyrolyzer. A diverse range of aromatics 
including benzene, toluene, xylenes, substituted benzenes, indanes, and naphthalene were produced through the catalytic pyrolysis of glucose, xylitol, cellobiose, and cellulose. The product selectivity was found dependent on both the pore size of the catalyst and the nature of the active sites. High heating rate and high catalyst loadings reportedly favored the production of aromatics over coke formation. Moreover, thermally stable oxygenates were formed at low catalyst-to-feed ratios. Overall, the authors concluded that the reaction conditions and catalyst properties were of utmost importance in maximizing the desired product selectivity.

Samolada et al. (2000) studied the comparative performance of alumina and HZSM-5 in a packed bed catalyst reactor with a synthetic bio-oil. The results revealed that alumina led to a high liquid yield of low compositional quality. On the contrary, HZSM-5 completely converted the undesirable carbonyls to hydrocarbons (with benzene, toluene, methyl-substituted benzenes, and indenes being dominant) but with decreased organic liquid yields. French and Czernik (2010) conducted catalytic upgrading of cellulose, lignin, and wood pyrolysis vapors using modified commercial and laboratory-synthesized zeolite-based catalysts in a tubular quartz micro-reactor. Compared to larger pore sized zeolites, i.e., alumina and Y zeolite, metal-doped ZSM-5 showed high activity for converting oxygenated pyrolysis vapors to hydrocarbons, and all the primary pyrolysis products except water and carbon oxides were converted mostly to hydrocarbons and coke. Mullen and Boateng (2015) claimed increases in the production of aromatic hydrocarbons from cellulose, cellobiose, and lignin applying iron-modified HZSM-5 in a microscale pyrolysis reactor coupled with GC/MS. Fischer et al. (2015) also found a considerably larger amount of aromatic hydrocarbons formed by using ZSM-5 during the pyrolysis of spent coffee grounds in both a fixed bed reactor and a pyroprobe. This result could be ascribed to decarbonylation reactions as the increased formation of aromatics with ZSM- 5 was accompanied by a slight increase in carbon oxide (Fischer et al., 2015). Sun et al. (2016) found a superior performance of Fe/ZSM-5 compared to ZSM-5 for catalytic fast pyrolysis of biomass using a Py-GC/MS. Fe/ZSM-5 showed excellent activity for conversion of oxygenates and formation of monocyclic aromatic hydrocarbons with increased yields of aromatic hydrocarbons from the bio-oil. In different evaluations, the effects of transition metal-modified $(\mathrm{Zn}, \mathrm{Co}$, and Ni) ZSM-5 for in-situ upgrading of pyrolysis vapors of rice straw were investigated. Accordingly, a pronounced effect of transition metal-modified ZSM-5 was observed in improving compound selectivity from bio-oil and in increasing the yield of bio-oil (Liang et al., 2017; Xiang et al., 2018).

Pattiya et al. (2008 and 2010) found ZSM-5 the most active catalyst for treatment of cassava rhizome biomass pyrolysis vapors in an analytical PyGC/MS. In this experiment, ZSM-5 enhanced the formation of aromatic hydrocarbons and phenols, decreased the amounts of oxygenated ligninderived compounds, and reduced the formation of carbonyl compounds. They linked aromatic production of ZSM-5 to its acidity together with its shape selectivity. However, as a side-effect of ZSM-5 catalyst, acetic acid was increasingly formed that could lower the $\mathrm{pH}$ value of the liquid. Engtrakul et al. (2016) also argued that the acidity of ZSM-5 had a strong influence on the selectivity of aromatic products during the upgrading of pine pyrolysis vapors in a micro-furnace pyrolyzer. Increasing the acidity of zeolite resulted in a reduction of alkylated aromatics, and increments in the formation of unsubstituted and polycyclic compounds. This phenomenon was attributed to the changes in the rate of cyclization and alkylation reaction.

On different aspects of ZSM-5 application, Thangalazhy-Gopakumar et al. (2012) and Lisa et al. (2012) reported increases in liquid hydrocarbons yields by increasing the ZSM-5 loading in an analytical pyrolysis-gas chromatography/mass spectrometry (Py-GC/MS) reactor. In addition to that, it should be noted that the preparation method used for zeolite-based catalysts could also play a key role in the properties of the resultant catalyst. For instance, the mesoporous ZSM-5 prepared by desilication (treatment with $\mathrm{NaOH}$ ) showed increased aromatic yields in catalytic pyrolysis of beech wood compared with the parent ZSM-5 (Li et al., 2014b).

\subsection{In-situ catalytic pyrolysis of biomass at bench/pilot scale}

Several researchers have studied different zeolite catalysts for in-situ catalytic biomass pyrolysis in bench scale experimental setups. Table 4 summarizes the influence of selected catalysts on product distribution of biomass pyrolysis. Despite the differences in biomass type and other operational parameters, the results obtained in these studies are remarkably consistent. For example, all of these investigations have confirmed that zeolite catalysts reduced the organic liquid yield compared to non-catalytic experiments, while water and gas yields were increased in general. Moreover, the majority of these studies have argued that coke formation was as a major deoxygenation route. For instance, Nyguyn et al. (2013) reported that the coke deposited on the catalyst had a high oxygen content of up to $41.5 \mathrm{wt} . \%$. Overall, there is a consensus in the results and the slight differences could be attributed to differences in catalyst/vapor contact associated with the different reactor types, type of biomass fed, catalyst-tobiomass ratio, and the other operational parameters, e.g., reactor temperature and vapor gas flow rate, etc.

As the characteristics of boil-oil, especially yield of oxygenated components and chemical composition of bio-oil, are of main interest for fuel application as well as for handling and storage properties, many researchers have described the effect of zeolite catalysts on bio-oil chemica composition in detail. A summary of the effects of zeolite on bio-oi chemical composition as reported in selected studies is presented in Figure 4. Aho et al. (2008) found that zeolite structure significantly affected the chemical composition of pine wood pyrolysis liquid using acidic zeolite catalysts, proton forms of Beta, Y, ZSM-5, and Mordenite in a fluidized bed reactor. Among the zeolite-based catalysts used, ZSM-5 produced the

Table 4.

Summary of the effects of zeolites on biomass pyrolysis products yields during in-situ catalytic pyrolysis.

\begin{tabular}{|c|c|c|c|c|c|c|c|c|}
\hline Catalyst & Feedstock & Reactor type & Bio-oil & Water & Gas & Char & Coke & Reference \\
\hline HZSM-5 & Pine Wood & Fluidized bed reactor & - & + & $\mathrm{n} / \mathrm{e}$ & - & + & Aho et al. (2008) \\
\hline HZSM-5 \& FCC & Lignocelluloses & Circulating fluidized bed reactor & - & + & + & + & + & Lappas et al. (2002) \\
\hline Co- ZSM-5 & Lignocelluloses & Circulating fluidized bed reactor & - & $\mathrm{n} / \mathrm{e}$ & + & + & + & Iliopoulou et al. (2014) \\
\hline HZSM-5 & Forest thinning & Bubbling fluidized bed reactor & - & $\mathrm{n} / \mathrm{e}$ & + & $\mathrm{n} / \mathrm{e}$ & & Paasikallio et al. (2013) \\
\hline $\begin{array}{l}\text { Co- ZSM-5 } \\
\text { Ni-ZSM-5 }\end{array}$ & Lignocelluloses & Circulating fluidized bed reactor & - & + & + & + & + & Iliopoulou et al. (2012) \\
\hline HZSM-5 & Sawdust & Conical spouted bed reactor & - & + & + & - & + & Atutxa et al. (2005) \\
\hline FCC & Lignocelluloses & Fluidized bed reactor & - & + & + & + & + & Antonakou et al. (2006b) \\
\hline HZSM-5 & Sawdust & Fluidized bed reactor & - & + & + & & + & Olazar et al. (2000) \\
\hline HZSM-5 \& FCC & Corncob & Fluidized bed reactor & - & $\mathrm{n} / \mathrm{e}$ & + & - & + & Zhang et al. (2009a) \\
\hline $\mathrm{Na}_{2} \mathrm{CO}_{3} / \gamma-\mathrm{Al}_{2} \mathrm{O}_{3}$ & Lignocelluloses & Entrained flow reactor & - & + & + & + & & Imran et al. (2014) \\
\hline
\end{tabular}

+ and - signs indicate increase and decrease in yield, respectively, $\mathrm{n} / \mathrm{e}$ indicates no or minimum effect, and blank columns indicate that no results were reported. 


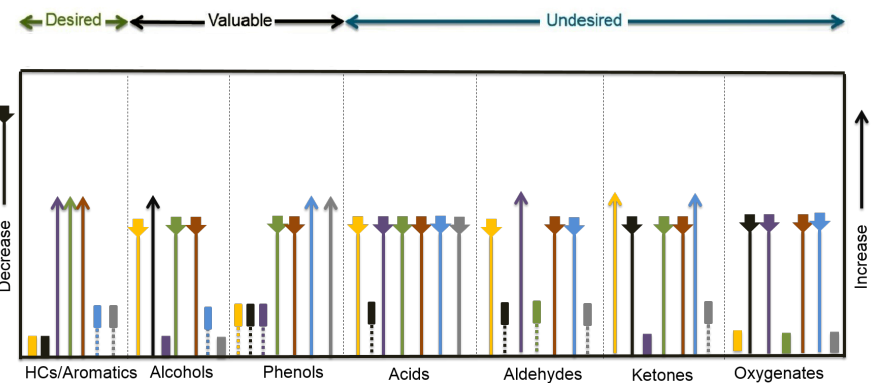

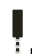

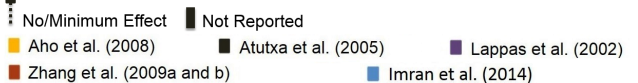

- Olazar et al. (2000) Iliopoulou et al. (2014)

Fig. 4. A summary of the results of selected studies on the effects of zeolites on chemical composition of bio-oil during in-situ catalytic pyrolysis.

highest amount of bio-oil comparatively. Moreover, it decreased the formation of acids while increased the formation of PAHs and ketones. All the zeolites investigated showed good regeneration behavior without changing the initial structures.

Jae et al. (2014) also showed that ZSM-5 was very stable through repeated reaction/regeneration cycles in a fluidized bed reactor and that high amount of aromatics was achieved. Yildiz et al. (2014) argued that, after successive regenerations, ZSM-5 retained sufficient activity in producing the target chemical components during the catalytic pyrolysis of pine wood in a benchscale auger reactor. They reported that fresh ZSM-5 formed aromatics, completely converted aldehydes and sugars, and reduced acids and ketones. In a more recent work, Yildiz et al. (2016) studied the catalytic pyrolysis of pine wood with various metal-doped ZSM-5 and $\gamma$-alumina in the same bench-scale auger reactor. All the catalysts enhanced water and coke formation at the expense of bio-oil yield. However, some of the catalysts remarkably improved the quality of bio-oil; especially the acidity of bio-oil was significantly decreased with increased deoxygenation. The lower redox-metal-containing acidic catalyst and freshly-calcined metal-doped basic catalysts showed the best performances.

Paasikallio et al. (2013) also reported that more aromatics compounds and fewer sugar compounds were obtained in bio-oil through the catalytic fast pyrolysis of forest thinning in a bench-scale bubbling fluidized bed reactor, and that bio-oil had considerably lower oxygen contents. Similarly using a benchscale bubbling fluidized bed reactor, Mante et al. (2014) examined ZSM-5 as a co-catalyst to Y-zeolite-based fluid cracking catalyst (FCC) for catalytic pyrolysis of hybrid poplar. They observed that the addition of ZSM-5 to the FCC increased organic liquid fraction and decreased coke/char and gas yields, while it enhanced the formation of aromatic compounds and decreased aliphatic hydrocarbons. Lappas et al. (2002) compared FCC and a ZSM-5 based FCC (zeolite content: $10 \mathrm{wt} . \%$ ) for catalytic fast pyrolysis of lignocellulosic biomass in a pilot scale circulating fluid bed reactor unit with continuous solids regeneration. Both catalysts reduced the oxygenated compounds and increased the hydrocarbons in the bio-oil. ZSM-5 produced more carbonyls, while the yields of acids, hydrocarbons, phenols, and heavy oxygenates were not significantly changed. Bertero and Sedran (2016) reported similar findings using FCC in a bench scale integrated fixed bed pyrolysis-conversion reactor for pyrolysis of soybean shell and pine sawdust. The yield of hydrocarbons in the bio-oil was increased by four folds compared to the non-catalytic bio-oil, with a higher selectivity to hydrocarbons in the typical range of gasoline with more olefins and less aromatic.

Iliopoulou et al. (2014) studied cobalt promoted ZSM-5 in a pilot scale circulating fluid bed reactor setup for in situ upgrading of lignocellulosic biomass pyrolysis vapors. Co-promoted ZSM-5 resulted in the formation of a three-phase bio-oil vs. the conventional two-phase (aqueous and organic phases) catalytic bio-oil. The third phase consisted mainly of aromatic hydrocarbons and phenolic compounds and was lighter than the aqueous phase. Cobalt addition significantly increased the formation of $\mathrm{CO}_{2}$ compared to $\mathrm{CO}$ and was suggested to have strongly enhanced aromatization reactions. In a previous work, Iliopoulou et al. (2012) reported similar effects with Ni-promoted ZSM-5 and that aromatics and phenols were increased in the bio-oil. Fermoso et al. (2016) and Hernando et al. (2017) studied the effect of Mg and Zn oxides modified ZSM-5 in a bench scale downdraft fixed-bed reactor for the catalytic fast-pyrolysis of eucalyptus woodchips. Compared to non-catalytic fast pyrolysis, the use of catalysts caused a decrease in the bio-oil yield due to enhanced formation of gases and formation of coke on the catalyst. However, the use of the catalyst produced a higher quality bio-oil with lower oxygen content and higher heating value. The modified ZSM-5 (with $\mathrm{MgO}$ and $\mathrm{ZnO}$ ) tailored the catalyst activity to avoid an excessive cracking of the bio-oil and resulted in a higher yield of the organic compounds in the bio-oil (with increased yield of monocyclic aromatics and decreased yield of coke). MgO-modified HZSM-5 achieved deeper deoxygenation and produced a bio-oil with higher energy value probably due to the adequate balance of Lewis acid and basic sites as a result of $\mathrm{MgO}$ addition.

Olazar et al. (2000) achieved considerable deoxygenation of bio-oil through catalytic pyrolysis of sawdust in a conical spouted bed reactor over HZSM-5 and found an increase in production of non-oxygenate hydrocarbons within the $\mathrm{C}_{5}-\mathrm{C}_{10}$ range as well as aromatics. In a later investigation, Atutxa et al. (2005) reported less oxygenated bio-oil produced from saw dust using HZSM-5 in a similar conical spouted bed reactor, though excessive coke formation on the catalyst was observed. For pyrolysis of corncob in a fluidized bed reactor over HZSM-5 and FCC, Zhang et al. (2009a and b) applied multi-stage condensation by collecting three different liquid fractions: heavy, light, and aqueous. The light oil fraction showed a considerable decrease in oxygen content and showed a remarkable increase in aromatic hydrocarbons content, while all other types of compounds were decreased. FCC reduced the amount of multifunctional components of phenols that are considered as likely polymerization precursors in the bio-oil. Such a remarkable improvement in the quality of light oil fraction could be attributed to the combined effect of catalyst application and multi-stage condensation. Imran et al. (2014) reported dramatic improvement in quality of catalytic bio-oil with a sodiummodified alumina. They obtained a highly deoxygenated bio-oil through insitu catalytic fast pyrolysis of biomass in a bench scale entrained flow reactor setup. Pyrolysis liquid showed a spontaneous separation into aqueous phase and organic phase (bio-oil). The undesired compounds in the bio-oil, i.e., acids, aldehydes, and sugars were completely converted and there were significant increases in the yields of phenols and ketones. The bio-oil had a very low oxygen content (16.4 wt.\%), water content as low as $5.8 \mathrm{wt} . \%$, a neutral $\mathrm{pH}$, and a high calorific value up to $36.1 \mathrm{MJ} / \mathrm{kg}$.

Overall, oxygenated compounds in bio-oil have been found to decrease in all the above-mentioned studies and undesired compounds were reduced in most cases using zeolites during in-situ catalytic biomass pyrolysis. Moreover, zeolites could generally result in significant reduction of acids which are responsible for low $\mathrm{pH}$ values of bio-oils. Aldehydes, contributors to poor stability of bio-oil, were also either reduced or unaffected in all the reported studies except that of Lappas et al. (2002) who claimed an increase in aldehydes content. The majority of these studies did not find any positive effects of zeolites on alcohol compounds in the biooil.

It should be noted that although all these studies (carried out at bench scale reactor systems) revealed positive effects of HZSM-5 and FCC catalysts on chemical composition of bio-oils, the improvements were not as pronounced as claimed at micro and analytical scaled studies (section 3.1.). This could be explained by the fact that most of micro and analytical scale studies were conducted with packed bed type catalyst systems and at relatively higher catalyst-to-biomass ratios. In another word, the less pronounced effect of HZSM-5 at bench scale units could be attributed to poor catalyst/vapor contact in fluidized bed type reactor systems and the lower catalyst-to-biomass ratios employed.

\subsection{Ex-situ catalytic pyrolysis of biomass at bench scale}

Ex-situ catalytic treatment of pyrolysis vapors over a packed bed of catalyst could address the many problems generally associated with in-situ 
Table 5.

Summary of biomass pyrolysis products yields and bio-oil composition during $e x$-situ upgrading of pyrolysis vapors over packed bed zeolites.

\begin{tabular}{|c|c|c|c|c|c|c|c|c|c|c|c|c|c|c|c|}
\hline Catalyst & Feedstock & $\begin{array}{l}\text { Catalyst reactor } \\
\text { type }\end{array}$ & Bio-oil & Water & Gas & Coke & HCs & PAHs & KETs & FURs & PHEs & ALCs & ACIDs & ALDs & Reference \\
\hline ZSM-5 & Rice husk & Packed bed & - & + & + & + & & & & & & & & & Williams and Nugranad (2000) \\
\hline $\begin{array}{l}\text { ZSM-5, Y } \\
\text { zeolite }\end{array}$ & Wood & Packed bed & - & + & + & + & & & & & & & & & $\begin{array}{l}\text { Williams and Horne (1994) } \\
\text { Horne and Williams (1995) } \\
\text { Williams and Horne (1995b) }\end{array}$ \\
\hline $\begin{array}{l}\text { ZSM-5, H-Y } \\
\text { and N-Z }\end{array}$ & Olive residue & Packed bed & - & & + & + & + & + & & & & & & & Pütün et al. (2009) \\
\hline H-ZSM5 & Beech wood & Packed bed & - & + & + & + & + & + & - & + & - & $\mathrm{n} / \mathrm{e}$ & - & $\mathrm{n} / \mathrm{e}$ & Stephanidis et al. (2011) \\
\hline H-ZSM-5 & Pine wood & Packed bed & $\mathrm{n} / \mathrm{e}$ & + & + & & + & & - & & + & - & - & - & Li et al. (2014a) \\
\hline
\end{tabular}

+ and - signs indicate the increase and decrease in yield respectively, $n / e$ indicates no or minimum effect, and blank column indicates the results are not reported.

HCs: Hydrocarbons; PAHs: Poly Aromatic Hydrocarbons; KETs: Ketones; FURs: Furans; PHEs: Phenols; ALCs: Alcohols; ALDs: Aldehydes.

catalytic pyrolysis. More specifically, since the ex-situ catalytic reaction is carried out inside a separate reactor, a more appropriate catalyst/vapor contact through higher catalyst-to-biomass ratios could be achieved. A considerable number of studies have been performed on ex-situ catalytic pyrolysis of biomass at bench scale in packed zeolite-based catalyst reactor systems. A summary of the effects of zeolites on pyrolysis products and chemical composition of bio-oil during ex-situ catalytic treatment of bio-oil vapors is presented in Table 5. As shown, all these investigations reported decreases in organic liquid yield with high levels of de-oxygenation and increases in water, gas, and coke yields. For instance, through upgrading of the fast pyrolysis vapors of olive residue in a two stage packed bed reactor using various catalysts (i.e., ZSM-5, H-Y, and natural zeolite (N-Z)), Putun et al. (2009) found reductions in oxygenated species of bio-oil. More specifically, the authors claimed that highly oxygenated polar groups and asphaltenes were dramatically decreased while alkanes and alkenes with long chains were effectively converted to lower molecular weight hydrocarbons and the amounts of aliphatics, aromatics, and olefins were increased in the bio-oil. Similar findings were also reported in a series of previous studies in which ZSM-5, Y-type zeolites, and activated alumina were found effective for deoxygenation of biooil during ex-situ upgrading of biomass vapors in packed bed reactors leading to enhanced formation of single ring aromatics and PAHs (Williams and Horne, 1994; Horne and Williams, 1995; Williams and Horne, 1995b; Williams and Nugranad, 2000). Williams and Nugranad et al. (2000) reported that the molecular weight distribution of bio-oil was decreased with ZSM-5. Stephanidis et al. (2011) also achieved enhanced formation of single ring and PAHs and significant deoxygenation of bio-oil produced by online vapor upgrading of lignocellulosic biomass pyrolysis vapors in a bench scale packed bed reactor of HZSM5 while the amount of acids, esters, aldehydes, ketones, and phenols were decreased.

Li et al. (2016) also reported improved generation of aromatic hydrocarbons in bio-oil with incorporating metal elements ( $\mathrm{Zr}, \mathrm{CO}$, and $\mathrm{Fe}$ ) on HZSM-5 for catalytic fast pyrolysis of sawdust in a vertical two-stage reactor. Metalmodified HZSM-5 showed superior catalytic activity for bio-oil upgrading compared to the parent HZSM-5 and metal-modified HZSM-5 produced biooil containing up to $45 \%$ aromatic hydrocarbons. Li et al. (2014a) performed pine wood pyrolysis in an auger reactor of $25 \mathrm{~kg} / \mathrm{h}$ capacity and carried out immediate treatment of pyrolysis vapor in a packed bed reactor of ZSM-5 ( $\mathrm{Li}$ et al., 2014a). Accordingly, ZSM-5 achieved a significant deoxygenation of the bio-oil, considerably increased the aromatics and phenol, and effectively removed the oxygenated compounds (such as acids, alcohols, carbonyls and carbohydrates) from the bio-oil.

In spite of the attempts made to date, a detailed analysis of the chemical composition of bio-oil is still lacking. Nevertheless and based on the findings of the studies reported above, it could be deduced that zeolites packed bed systems are capable of efficient deoxygenation of bio-oil; enhanced formation of hydrocarbons/aromatics (i.e., the most desired compounds for fuel applications), and reduced formation of acids (i.e., the most undesired compounds in bio-oil). However, it should also be noted that packed bed reactor system is not a viable option to scale up for commercial applications due to difficulties in continuous regeneration of the catalyst compared to available commercial reactor systems, e.g., fluidized bed reactors.

\section{Mesoporous aluminosilicates for catalytic biomass pyrolysis}

Mesoporous aluminosilicates have a uniform pore structure with pore sizes much larger than those of zeolites, high surface area, and moderate acidity compared to zeolites. Mesoporous aluminosilicates have gained a considerable deal of interest over last years for catalytic pyrolysis of biomass. This has been ascribed to the possibility of better matching the size of oligomers derived from the initial thermal degradation of biomass with the pore size of the catalyst. In better words, due to their large pore size and mild acidity, mesoporous aluminosilicates are expected to perform selective cracking and deoxygenation of large molecules as of lignin derived compounds without reducing organics yields significantly and without being quickly deactivated by coking (Antonakou et al., 2006a). Among these catalysts, MCM-41 exhibits extremely high surface areas $\left(1000 \mathrm{~m}^{2} / \mathrm{g}\right.$ and larger) and well-defined pore sizes with a relatively narrow pore size distribution in the range of 20-30 $\AA$ (Beck et al., 1992). These attributes of MCM-41 materials could be obtained by controlling the preparation conditions, such as reaction temperature, reaction time, as well as the pH value (Bridgwater, 1999). MCM-41 has been frequently used to catalyze specific reactions concerning bio-oil, such as the hydroxylation and alkylation of phenol (Noreña-Franco et al., 2002; Savidha et al., 2004), oxidation and isomerization of hexane (Carvalho et al., 1999; Chaudhari et al., 1999), oxidation and dehydrogenation of hydrocarbons (Parvulescu and Su, 2001; Nesterenko et al., 2003), and hydrogenation of aromatics (Corma et al., 1997; Albertazzi et al., 2004).

\subsection{Effect of different metal incorporation to mesoporous aluminosilicates}

Since the first synthesis of MCM-41, much work has been carried out in incorporating various elements $(\mathrm{Ni}, \mathrm{Al}, \mathrm{Co}, \mathrm{Mo}, \mathrm{Fe}, \mathrm{Cu})$ together with silicon into the framework of MCM-41 to change the physicochemical properties of the material, especially to improve the acidic characteristics (Lewandowska et al., 2002). Al-doped MCM-41 is the most predominantly studied aluminoslilicate for catalytic biomass pyrolysis. Using a synthetic bio-oil, Samolada et al. (2000) found the catalytic activity of Al-doped MCM-41 comparable to that $\gamma-\mathrm{Al}_{2} \mathrm{O}_{3}$. More specifically, the developed catalysts retained a high liquid yield but it could not contribute to any considerable improvements to the liquid product composition. Iliopoulou et al. (2007) studied Al-MCM-41 for biomass pyrolysis vapor upgrading in a bench scale packed bed reactor and found reductions in the amounts of the undesirable compounds, such as acids and heavy compounds; and enhanced formation of desirable compounds, such as hydrocarbons and phenols. Moreover, they argued that Al-MCM-41 effectively converted high molecular weight lignocellulosic molecules into lighter fractions. The promising activity of the catalyst was attributed to its mild acidity, large surface area, and tubular mesopores. Adam et al. (2005 and 2006) reported very similar performance of various mesoporous catalysts including 
Al-MCM-41 during upgrading lignocellulosic biomass pyrolysis vapors in an analytical Py-GC/MS setup with packed bed catalyst. Accordingly, all mesoporous catalysts reduced the amounts of undesirable compounds in the bio-oil, e.g., carbonyl and acid, while higher contents of desirable compounds were obtained in the organic phase, e.g., hydrocarbons. They also argued that increasing the pore size of Al-MCM-41 caused water and undesirable products formation.

Stephanidis et al. (2011) found catalytic effect of Al-MCM-41 somewhat similar to that of H-ZSM-5 for online upgrading of lignocellulosic biomass pyrolysis vapors in a small bench scale packed bed catalyst reactor but significantly higher coke was deposited on the catalyst. Yields of acids, esters, aldehydes, ketones, and phenols were decreased while the single ring and poly aromatics concentrations were increased significantly using Al-MCM-41. Pattiya et al. (2008 and 2010) compared ZSM-5, Al-MCM-41, and Al-MSU-F (a large pore size $(>100 \AA)$ aluminosilicate catalyst) for cassava rhizome pyrolysis vapor treatment using an analytical Py-GC/MS setup. Catalytic activities of Al-MSU-F and Al-MCM-41 were reportedly very similar to that of ZSM-5. Moreover, Al-MSU-F and Al-MCM-41 produced aromatic hydrocarbons and reduced the oxygenated lignin derivatives and phenols. AlMSU-F produced more hydrocarbons, particularly benzene and xylenes, than Al-MCM-41. This phenomenon was attributed to the large pores of Al-MSUF that would allow large pyrolysis molecules to enter, react, and exit the catalyst matrix. A drawback noticed with aluminosilicate was the increase in the formation of acids (Pattiya et al., 2008 and 2010).

Independent of the $\mathrm{Al}$ content in the framework, the MCM-41 shows a weak acidity comparable to amorphous aluminosilicates (Ciesla and Schüth, 1999). The presence of aluminium can improve the acidic and cracking characteristics of MCM-41 (Twaiq et al., 2003). It is worth mentioning that Si/Al ratio of AlMCM-41 could also play an important role in the activity of the catalyst. More specifically, higher $\mathrm{Si} / \mathrm{Al}$ ratios reportedly increased the organic phase of the pyrolysis bio-oil, while lower $\mathrm{Si} / \mathrm{Al}$ ratios enhanced the conversion of bio-oil to gases and coke formation while also increased the yield of high value aromatic compounds (Antonakou et al., 2006a; Iliopoulou et al., 2007).

In addition to aluminum, successful application of other metal elements have also been reported such as Fe by He et al. (1997), Ti by Corma et al. (1994a and b), V by Luan et al. (1996), Cu by Wu et al. (2001) and Noreña-Franco et al. (2002), and Zn by Selvaraj et al. (2004). It has been found that the catalytic properties of mesoporous materials could be generally improved by the incorporation of these metal elements (Corma, 1995; Takeguchi et al., 1998; Occelli et al., 1999). Antonakaou et al. (2006a) found increased yields of hydrocarbons and PAHs through biomass pyrolysis over $\mathrm{Cu}-\mathrm{MCM}-41, \mathrm{Fe}-$ MCM-41, and Zn-MCM-41 in a packed bed reactor. Fe-MCM-41 and $\mathrm{Cu}-$ MCM-41 were revealed as most promising metal-containing catalysts for phenols production while Fe-MCM-41 reduced the carbonyl production. Moreover, only Cu-MCM-41 was successful to reduce acids and esters production, while $\mathrm{Fe}-\mathrm{MCM}-41$ and $\mathrm{Zn}-\mathrm{MCM}-41$ increased the alcohols yields. $\mathrm{Cu}-\mathrm{MCM}-41$ was also tested resulting in the highest gas production and less water production compared to the parent MCM-41.

The catalytic effects of different mesoporous aluminosilicates on yield and chemical composition of upgraded bio-oil are summarized in Table 6. In conclusion, the performance of aluminosilicates in terms of the yields of biomass pyrolysis products would be relatively comparable to that of zeolites. More specifically, both tend to produce desirable compounds in the bio-oil and reduce the undesirable compounds in the bio-oil. However, compared to zeolites, larger pore sized aluminosilicates reduce catalys deactivation as larger pores allow larger molecules, such as lignin-derived compounds, to enter, reform, and exit the catalyst with less chance of coke deposition.

\section{Alkaline compounds for catalytic pyrolysis of biomass}

There are more than 19 inorganic species identified in biomass (Saijonkari-Pahkala, 2001). It is well known that some of these inorganic constituents of biomass including alkali metals and alkaline earth metals could act as catalyst during thermal degradation of biomass in pyrolysis process, determining the rate of thermal decomposition and yield of char (Czernik and Bridgwater, 2004). It has been reported that the inorganic content of biomass could accelerate the secondary cracking reactions breaking down higher molecular compounds to smaller ones (Bradbury et al., 1979). It should be noted that since some alkaline compounds (alkali and alkaline earth metals) including potassium, sodium, calcium, and magnesium are abundant in a variety of biomass, attentions have been paid to their catalytic effects from viewpoints of chemistry and application.

\subsection{Alkali metal-based catalysts for catalytic pyrolysis of biomass}

Extensive research has been carried out on the effect of alkali metals on the decomposition behavior of biomass under thermal degradation which in turn could affect the conversion of biomass during pyrolysis process. It has been shown that the main alkali metals of plant origin affecting pyrolysis degradation include sodium, potassium, and magnesium (Raveendran et al., 1995; Liden et al., 1988; Czernik and Bridgwater, 2004). For instance, $\mathrm{NaCl}$ present in biomass even at trace concentration of around $0.1 \mathrm{wt} . \%$ has been shown to impact the biomass pyrolysis product distribution (White et al., 2011). From the mechanism point of view, these cation moieties of the salts affect the thermal decomposition of biomass during fast pyrolysis through primary fragmentation of the polymer chains (Jahirul et al., 2012) Raveendran et al. (1995) argued that the cations would exert more influence on the catalytic pyrolysis of biomass compared to their anion counterparts.

Alkali metals have been found strongly favorable for the formation of low molecular weight compounds by conversion of levoglucosan in biomass pyrolysis, Fahmi et al. (2007) found higher levoglucosan yields and the lower hydroxyacetaldehyde yields in a Py-GC/MS when alkaline metal content of biomass was decreased by washing. Liden et al. (1988 reported similar results for thermal degradation of cellulose and found that high levels of alkali metals favored fragmentation (ring scission) producing lower molecular weight compounds such as hydroxyacetaldehyde, while lower alkali metal contents favored de-polymerisation resulting in higher molecular weight compounds such as levoglucosan and $\beta$-D-fructose.

Table 6.

Summary of biomass pyrolysis products yields and bio-oil composition during upgrading of pyrolysis vapors over packed bed mesoporous aluminosilicates.

\begin{tabular}{|c|c|c|c|c|c|c|c|c|c|c|c|c|c|c|c|}
\hline Catalyst & Feedstock & Bio-oil & Water & Gas & Char & Coke & HCs & PAHs & KETs & FURs & PHES & ALCs & ACIDs & CANs & Reference \\
\hline $\mathrm{Cu}-\mathrm{MCM}-41$ & Lignocelluloses & - & + & - & & + & - & + & $\mathrm{n} / \mathrm{e}$ & + & $\mathrm{n} / \mathrm{e}$ & - & & + & Antonakou et al. (2006a) \\
\hline Fe-MCM-41 & Lignocelluloses & - & + & - & & + & - & + & $\mathrm{n} / \mathrm{e}$ & + & - & $\mathrm{n} / \mathrm{e}$ & & - & Antonakou et al. (2006a) \\
\hline Zn-MCM-41 & Lignocelluloses & - & + & - & & + & - & + & $\mathrm{n} / \mathrm{e}$ & $\mathrm{n} / \mathrm{e}$ & - & + & & + & Antonakou et al. (2006a) \\
\hline Al-MCM-41 & Wood & - & + & $\mathrm{n} / \mathrm{e}$ & & + & + & + & + & + & & - & - & - & Adam et al. (2006); Adam et al. (2005) \\
\hline $\mathrm{Cu}-\mathrm{Al}-\mathrm{MCM}-41$ & Wood & $\mathrm{n} / \mathrm{e}$ & $\mathrm{n} / \mathrm{e}$ & + & & + & + & + & + & + & & - & - & - & Adam et al. (2006); Adam et al. (2005) \\
\hline Al-MCM-41 & Wood & - & + & $\mathrm{n} / \mathrm{e}$ & & + & + & + & & + & $\mathrm{n} / \mathrm{e}$ & - & & + & Iliopoulou et al. (2007) \\
\hline Al-MCM-41 & Beech wood & + & + & - & $\mathrm{n} / \mathrm{e}$ & - & + & + & $\mathrm{n} / \mathrm{e}$ & - & $\mathrm{n} / \mathrm{e}$ & $\mathrm{n} / \mathrm{e}$ & + & & Stephanidis et al. (2011) \\
\hline
\end{tabular}

+ and - signs indicate the increase and decrease in yield respectively, n/e indicates no or minimum effect, and blank column indicates the results are not reported.

HCs: Hydrocarbons; PAHs: Poly Aromatic Hydrocarbons; KETs: Ketones; FURs: Furans; PHEs: Phenols; ALCs: Alcohols; CANs: Carbonyls. 
It is believed that wet impregnated alkali metal could affect the primary decomposition reactions and control the nature of the biomass thermal degradation products. In line with that, Di Blasi et al. (2006, 2008, and 2009b) investigated the catalytic pyrolysis of wet impregnated alkali compounds $\left(\mathrm{NaOH}, \mathrm{KOH}, \mathrm{Na}_{2} \mathrm{CO}_{3}, \mathrm{~K}_{2} \mathrm{CO}_{3}, \mathrm{KC}_{2} \mathrm{H}_{3} \mathrm{O}_{2}\right.$, and $\mathrm{NaCl}$ ) onto wood in a fixed-bed reactor. Accordingly, alkali compounds lowered the organics yield in the liquid phase and increased the yields of char, gases, and water. Moreover, the alkali compounds impregnation lowered the temperature of wood decomposition and time of conversion and these effects were enhanced by increasing the basicity of alkali compound (Wang et al., 2006). In a similar work on catalytic pyrolysis of fir wood in a packed-bed reactor, higher concentrations of $\mathrm{KOH}$ impregnated onto the wood lowered the decomposition temperatures of the wood and increased the production of char, water, and $\mathrm{CO}_{2}$ at the expense of organics in the liquid (Di Blasi et al., 2009a). Jensen et al. (1998) and Nowakowski et al. (2007) also observed that potassium impregnation onto wheat straw and short rotation willow coppice enhanced the yields of gaseous product of the pyrolysis, with an increase in the yields of char. Raveendran et al. (1995) also reported increase in char during pyrolysis of $\mathrm{KCl}$ or $\mathrm{K}_{2} \mathrm{CO}_{3}$ impregnated biomass samples.

The easiest and most economical way for implementation of wet impregnation of alkali metals in catalytic pyrolysis of biomass is physical mixing. It should be noted that physically mixed alkali metals are less likely to influence primary decomposition reaction of biomass pyrolysis and their catalytic activity is limited to secondary reforming of bio-oil vapors. Some successful examples are presented and discussed herein. Wang et al. (2010) studied the catalytic effect of physically mixed $\mathrm{K}_{2} \mathrm{CO}_{3}$ and $\mathrm{Ca}(\mathrm{OH})_{2}$ on pyrolysis of pine wood in a packed bed reactor. They reported that $\mathrm{K}_{2} \mathrm{CO}_{3}$ lowered the decomposition of hemicellulose and cellulose, reduced liquid yields, and increased the yields of gaseous and char products, while $\mathrm{Ca}(\mathrm{OH})_{2}$ completely removed the acids and aldehydes from the bio-oil with a significant increase in yield of alcohols without significantly affecting the yields of the other pyrolysis products. Imran et al. (2016) used physically mixed $\mathrm{Na}_{2} \mathrm{CO}_{3}$ for in-situ catalytic fast pyrolysis of Jatropha seed cake in a bench scale entrained flow reactor setup. In their study, a spontaneous separation of aqueous phase and organic phase (bio-oil) was observed. Moreover, the undesired compounds, i.e., acids and aldehydes, were completely removed from the bio-oil and there was a dramatic increase in the aliphatic and aromatic hydrocarbons content. They also claimed that the upgraded bio-oil had a very low oxygen and water contents (7.1 and $6.8 \mathrm{wt} . \%$, respectively), a neutral $\mathrm{pH}$, and a high calorific value of up to $36.7 \mathrm{MJ} / \mathrm{kg}$. The authors attributed these considerable improvements to the synergetic effect of $\mathrm{Na}_{2} \mathrm{CO}_{3}$ and triglycerides content of Jatropha cake (Imran et al., 2016).
In spite of the research works conducted on the effect of alkali metals on biomass primary decomposition, there is still a lack of systematic studies on the effect of alkali metals on the characteristics and chemical composition of the upgraded bio-oil. A summary of the catalytic effect of alkaline compounds on yields of biomass pyrolysis products and on bio-oi composition is presented in Table 7. In conclusion, alkali metals are capable of reducing undesired compounds of bio-oil particularly acids and enhancing the formation of some types of phenols which are regarded as high value products. Moreover, alkali metals could have a clear effect on lowering the biomass thermal degradation temperature.

\subsection{Alkaline earth metal-based catalysts for catalytic pyrolysis of biomass}

Alkaline earth metals have been extensively studied as tar cracking catalyst in gasification and the use of these base materials could be extended to upgrading of biomass pyrolysis oils. Alkaline earth metals are found in form of minerals and can be applied directly for catalysis without chemical treatment. The advantages of these materials are that they are abundant and are inexpensive compared to synthetic catalysts. The uncalcined forms of these materials are called limestone $\left(\mathrm{CaCO}_{3}\right)$, magnesium carbonate $\left(\mathrm{MgCO}_{3}\right)$, and dolomite $\left(\mathrm{CaCO}_{3} \cdot \mathrm{MgCO}_{3}\right)$. These materials show high catalytic activities for tar elimination when calcined. Calcination is a process where bound carbon dioxide is released upon heating. Calcined forms include calcites, magnesites, and calcined dolomites. Taralas and Kontominas (2004) studied the catalytic pyrolysis of toluene with Norwegian dolomitic magnesium oxide [MgO], Swedish low surface quicklime [CaO], and calcined dolomite $\left[\mathrm{CaMg}(\mathrm{O})_{2}\right]$ and found the performance of all mineral catalysts superior to that of metal modified alumina $\left(\mathrm{NiMo} / \gamma-\mathrm{Al}_{2} \mathrm{O}_{3}\right) ;$ in the following order: $\mathrm{CaO}>\mathrm{CaMg}(\mathrm{O})_{2}>\mathrm{MgO}>$ alumina.

Calcined limestone could be a potential catalyst for catalytic upgrading of bio-oil. Catalytic pyrolysis of Mahua seed (Shadangi and Mohanty, 2014a) and Karanja tree (Shadangi and Mohanty, 2014b) with $\mathrm{CaO}$ was investigated leading to the production of a bio-oil with high $\mathrm{pH}$, viscosity, and heating value. Ding et al. (2009) reported that $\mathrm{CaO}$ could increase catalytic decarboxylation by conversion of acid compounds to hydrocarbons. Lu et al. (2010) used various metal oxides for reforming of poplar wood pyrolysis vapors in a Py-GC/MS. They claimed that $\mathrm{CaO}$ removed the acids, reduced the heavy products like anhydrosugars, while it increased the formation of desired compounds such as cyclopentanones, hydrocarbons, and several light compounds like acetaldehyde, acetone, 2 butanone, and methanol. Lin et al. (2010) used $\mathrm{CaO}$ to study the effect of

Table 7.

Summary of catalytic effect of alkaline compounds on yields of biomass pyrolysis products and bio-oil composition.

\begin{tabular}{|c|c|c|c|c|c|c|c|c|c|c|c|c|c|c|c|}
\hline Catalyst & Feedstock & $\begin{array}{l}\text { Impregnation } \\
\text { method }\end{array}$ & Reactor type & Bio-oil & Water & Gas & Char & HCs & CANs & FURs & PHEs & ALCs & ACIDs & ALDs & Reference \\
\hline $\mathrm{K}_{2} \mathrm{CO}_{3}$ & Pine wood & $\begin{array}{l}\text { Physically } \\
\text { mixed }\end{array}$ & $\begin{array}{l}\text { Packed-bed } \\
\text { reactor }\end{array}$ & - & & + & + & + & & - & + & - & - & - & Wang et al. (2010) \\
\hline $\begin{array}{l}\mathrm{NaOH}, \mathrm{KOH}, \\
\mathrm{Na}_{2} \mathrm{CO}_{3}, \mathrm{~K}_{2} \mathrm{CO}_{3}, \\
\mathrm{KC}_{2} \mathrm{H}_{3} \mathrm{O}_{2} \text {, and } \mathrm{NaCl}\end{array}$ & Wood & $\begin{array}{l}\text { Wet } \\
\text { impregnation }\end{array}$ & $\begin{array}{l}\text { Packed-bed } \\
\text { reactor }\end{array}$ & - & + & + & + & & + & - & + & & & & $\begin{array}{l}\text { Di Blasi et al. (2007); } \\
\text { Di Blasi et al. (2008); } \\
\text { Di Blasi et al. (2009b) }\end{array}$ \\
\hline $\mathrm{KOH}$ & Fir wood & $\begin{array}{l}\text { Wet } \\
\text { impregnation }\end{array}$ & $\begin{array}{l}\text { Packed-bed } \\
\text { reactor }\end{array}$ & - & + & + & + & & + & & + & & & & Di Blasi et al. (2009a) \\
\hline $\mathrm{Na}_{2} \mathrm{CO}_{3}$ & $\begin{array}{l}\text { Jatropha } \\
\text { seed cake }\end{array}$ & $\begin{array}{l}\text { Physically } \\
\text { mixed }\end{array}$ & $\begin{array}{l}\text { Entrained } \\
\text { flow reactor }\end{array}$ & - & + & + & + & + & & - & - & - & - & - & Imran et al. (2016) \\
\hline $\mathrm{MgO}$ & $\begin{array}{l}\text { Cotton } \\
\text { seed }\end{array}$ & N/A & $\begin{array}{l}\text { Tubular } \\
\text { Packed Bed } \\
\text { reactor }\end{array}$ & - & & + & + & + & & & & & & & Pütün (2010) \\
\hline $\mathrm{CaO}$ & Pine wood & N/A & $\begin{array}{l}\text { Fluidized-bed } \\
\text { reactor }\end{array}$ & - & + & - & + & & & + & + & & - & & Lin et al. (2010) \\
\hline $\mathrm{Ca}(\mathrm{OH})_{2}$ & Pine wood & $\begin{array}{l}\text { Physically } \\
\text { mixed }\end{array}$ & $\begin{array}{l}\text { Packed Bed } \\
\text { reactor }\end{array}$ & + & & - & + & & & - & & + & - & - & Wang et al. (2010) \\
\hline $\mathrm{CaO}$ & Wood & N/A & Py/GC-MS & & & & & + & & - & - & + & - & $\mathrm{n} / \mathrm{e}$ & Lu et al. (2010) \\
\hline
\end{tabular}

+ and - signs indicate the increase and decrease in yield respectively, n/e indicates no or minimum effect, and blank column indicates the results are not reported

HCs: Hydrocarbons; CANs: Carbonyls; FURs: Furans; PHEs: Phenols; ALCs: Alcohols; ALDs: Aldehydes. 
catalyst-to-biomass ratios for in-situ deoxygenation of pine wood pyrolysis vapors in a fluidized-bed reactor. They found that high catalyst-to-biomass ratios lowered the oxygen content of bio-oil while water content of the bio-oil was almost doubled. Moreover, $\mathrm{CaO}$ reduced the gas yields from $19 \%$ to $10 \%$ and this reduction was attributed to the absorption of $\mathrm{CO}_{2}$ on $\mathrm{CaO}$ forming $\mathrm{CaCO}_{3}$. While dramatic decreases were observed in the yield of some liquid phase compounds including laevoglucose, D-allose, and acidic compounds.

Pütün (2010) applied $\mathrm{MgO}$ for catalytic pyrolysis of cotton seed in a tubular packed bed and found decreases in oil yields whereas increases in gas and char yields were recorded. However, the quality of bio-oil was improved in terms of calorific value, hydrocarbon distribution, and removal of oxygenated groups. In addition to that, they also stated that $\mathrm{MgO}$ removed up to $50 \%$ of oxygen, converted long chain alkanes and alkenes to lower molecular weight hydrocarbons, and increased the aliphatic and aromatic fractions of the bio-oil. Stefanidis et al. (2016) compared the performance of MgO and ZSM-5 for catalytic pyrolysis of beech wood sawdust in a bench-scale fixed bed tubular reactor. Accordingly, $\mathrm{MgO}$ effectively decreased the oxygen content of the biooil and exhibited similar or even better performance compared to that of ZSM5. Analyzing product distribution and the composition of the bio-oil revealed that the basic sites of the $\mathrm{MgO}$ favored the reduction of acids and deoxygenation via ketonization and aldol condensation reactions, removing oxygen mainly as $\mathrm{CO}_{2}$. $\mathrm{MgO}$ also exhibited better regeneration characteristics upon coke combustion compared to that of ZSM-5. Zhang et al. (2014) reported significant increases in the yield of aromatics in bio-oil, when studied the synergistic effect of the addition of $\mathrm{MgO}, \mathrm{CaO}$, spent $\mathrm{FCC}$, and ZSM-5 during the pyrolysis of pine sawdust in a Py-GC/MS. The addition of these base catalysts led to efficient cracking of high-oxygenated compounds into low oxygenated compounds and with the subsequent conversion of the low oxygenated compounds into aromatics. Veses et al. (2014) applied dolomite and $\mathrm{CaO}$ for in-situ upgrading of wood pyrolysis in an auger reactor and recorded remarkable decreases in oxygen content and acidity of the bio-oil and the resulted bio-oil had a higher $\mathrm{pH}$ and calorific values.

Overall, research on the effect of alkaline earth metal-based catalysts on biomass pyrolysis is very limited and a lot more needs to be done to evaluate their potentials for biomass pyrolysis in general and for biofuels production in particular. Nevertheless, the preliminary studies have shown their potential for deoxygenation of bio-oil and positive indication to produce more desirable compounds in bio-oil such as alkanes and aromatics with suppressed formation of undesirable compounds such as acids. In general, alkaline earth metals lead to decreased bio-oil yields and increased water and char yields. It should be noted that the main interest in application of these mineral compounds in biomass catalytic pyrolysis lies in their abundance in nature and being inexpensive, favoring the economic aspects of biofuels production.

\section{Catalytic fast pyrolysis of biomass at pilot and demonstration scale}

Recently, a few activities have been initiated to implement catalytic fast pyrolysis at industrial demonstration scale. KiOR Inc. announced their start-up production unit in Mississippi using their biomass fluidized catalytic cracking (BFCC) process with a capacity of 500 ton/d biomass, yielding 67 gallon biooil/ton of biomass (KiOR, 2016). It is infect a FCC-type process where catalyst is employed replacing a proportion of the heating media (sand) in a fluidized bed reactor and the coked catalyst is regenerated in a combustor. There is not much information available on the catalyst type and product quality but KiOR claimed to produce gasoline and diesel blend stocks using their catalyst through the BFCC process. Moreover, they argue that the products are comparable to their fossil-oriented counterparts. RTI International (Research Triangle Institute) has also developed such a catalytic biomass pyrolysis process with 1 ton/d biomass capacity. The pilot plant is based on a single-loop transport reactor design with continuous catalyst circulation and regeneration (Dayton et al., 2015) and has been successfully operated with a novel catalyst producing a bio-crude intermediate with $24 \mathrm{wt} . \%$ oxygen.

Another successful example is the novel cyclonic reactor system "PyRos" which was adopted for online in-situ catalytic pyrolysis of biomass (Brem and Bramer, 2007). Cyclonic reactor provides the substantial advantage of a very short vapor residence time (less than half a second) over existing pyrolysis technologies, e.g., fluidized bed reactor systems, and can considerably improve the liquid yields and properties by avoiding excessive secondary cracking and contact of vapors with coke and char. The schematic presentation of the process is depicted in Figure 5. It is also a FCC-type process that could provide a

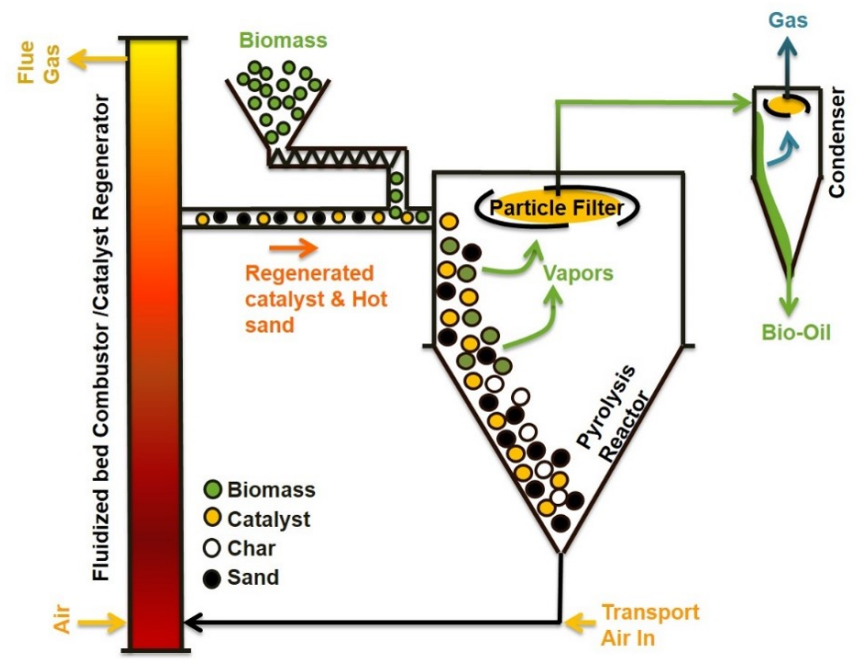

Fig. 5. The schematic presentation of the PyRos Reactor System.

suitable solution for continuous production of bio-fuel and regeneration of coked catalyst. PyRos has also introduced a novel sodium-based alumina catalyst whose product characteristics have been reported based on a lab scale testing unit (Imran et al., 2014). The preliminary findings showed that this catalyst could be implemented in the current pilot scale pyrolysis technologies and could be scaled up for commercial production of biofuels. A reactor concept with a mobile catalyst phase and an integrated catalyst regeneration unit seems to be a promising option for the scale up of this technology. A conceptual process flow sheet for the production of green fuels via catalytic fast pyrolysis is presented in the graphical abstract of this article that may be integrated with the existing refinery structure.

Apparently, catalyst development is key for the success of commercial production of biofuels and a breakthrough in catalyst development could be instrumental. Based on the present review, zeolites could be considered as the most extensively studied catalysts for catalytic biomass pyrolysis and hold the highest potential to tailor the bio-oil properties for biofuels application. The main problems that need to overcome with zeolites are, to avoid deep cracking and formation of gas which reduces liquid yields, to avoid deep deoxygenation that yields a polyaromatic product, and to avoid severe catalyst deactivation due to coke formation. Deep cracking and formation of gas may be controlled by manipulating the strength and concentration of acid sites in zeolites. Formation of polyaromatics may not be avoided as it arises from the low hydrogen content of biomass. From this point of view, a selective deoxygenation, which leaves behind part of the oxygen in the bio-oil may be a more attractive option. Only, the resulting mixture should be made suitable for blending with hydrocarbon fuels for further processing. Formation of coke and catalyst deactivation is not a major problem in an FCC-type pyrolysis operation, where combustion of coke deposited on the catalyst generates the energy required to run the endothermic cracking process. Up to date, research on catalytic pyrolysis of biomass has shown promising results but further studies are required to design a more dedicated catalyst to carry out selective deoxygenation of the bio-oil and to maximize yield of diesel and gasoline range hydrocarbons.

\section{Concluding remarks and future prospects}

Zeolites are capable of reducing the concentration of oxygenated compounds present in biomass pyrolysis liquid via deoxygenation reactions (such as dehydration, decarbonylation, and decarboxylation), while increasing the concentration of hydrocarbon and aromatic species. Another advantage of zeolites is decreased molecular weight of the bio-oil through cracking lignin-derived compounds. Nevertheless, there are also drawbacks associated with the application of relatively small pore sized zeolites including significant decreases in the yield of the organic phase of bio-oi 
caused by increased production of water and gas as well as by rapid catalyst deactivation through coke deposition. Compared to zeolites, larger pore sized aluminosilicates are less susceptible to catalyst deactivation and therefore, relatively higher organic yields could be expected. However, it should be noted that the performance of the aluminosilicates has not always been found superior to that of the conventional zeolites. In general, these mesoporous catalysts have been revealed to possess less activity compared to ZSM-5 under the same conditions. Overall and as a key point, a careful tuning of the pore size and acidity of these catalysts could improve their product selectivity.

Studies on the effects of alkaline compounds addition on the pyrolysis of lignocellulosic materials are not extensive and their catalytic effects on the characteristics of biomass pyrolysis products are yet to be systematically investigated. A detailed analysis of bio-oil characteristics is also lacking. Such information would be needed to evaluate the potentials of alkaline compounds for their implementation as catalyst for biofuels production. Nevertheless, some of their qualitative features are well evident revealing that alkali metals could result in increases in yields of char, gas, and water as well as reductions in organic liquid contents owing to enhancements in dehydration, decarboxylation, and charring reactions. Moreover, alkali metals are also effective on converting higher molecular weight compounds such as levoglucosan into lower molecular weight compounds formation. Finally, the preliminary findings have revealed the potentials of alkaline earth metals for deoxygenation of bio-oil, production of hydrocarbons, and reduction of undesired compounds in particular acids. Nevertheless, further systemic studies would be required to explore their full catalytic potential for production of biofuels.

\section{References}

[1] Adam, J., Antonakou, E., Lappas, A., Stöcker, M., Nilsen, M.H., Bouzga, A., Hustad, J.E., Øye, G., 2006. In situ catalytic upgrading of biomass derived fast pyrolysis vapours in a fixed bed reactor using mesoporous materials. Microporous Mesoporous Mater. 96(1-3), 93101

[2] Adam, J., Blazsó, M., Mészáros, E., Stöcker, M., Nilsen, M.H., Bouzga, A., Hustad, J.E., Grønli, M., Øye, G., 2005. Pyrolysis of biomass in the presence of Al-MCM-41 type catalysts. Fuel. 84(12-13), 1494-1502.

[3] Adjaye, J.D., Bakhshi, N.N., 1995. Production of hydrocarbons by catalytic upgrading of a fast pyrolysis bio-oil. Part I: conversion over various catalysts. Fuel Process. Technol. 45(3), 161-183.

[4] Aho, A., Kumar, N., Eränen, K., Salmi, T., Hupa, M., Murzin, D.Y., 2008. Catalytic pyrolysis of woody biomass in a fluidized bed reactor: influence of the zeolite structure. Fuel. 87(12), 2493-2501.

[5] Albertazzi, S., Rodríguez-Castellón, E., Livi, M., Jiménez-López, A., Vaccari, A., 2004. Hydrogenation and hydrogenolysis/ring-opening of naphthalene on Pd/Pt supported on zirconium-doped mesoporous silica catalysts. J. Catal. 228(1), 218-224.

[6] Antonakou, E., Lappas, A., Nilsen, M.H., Bouzga, A., Stöcker, M., 2006. Evaluation of various types of Al-MCM-41 materials as catalysts in biomass pyrolysis for the production of bio-fuels and chemicals. Fuel. 85(14-15), 2202-2212

[7] Antonakou, E.V., Dimitropoulos, V.S., Lappas, A.A., 2006. Production and characterization of bio-oil from catalytic biomass pyrolysis. Therm. Sci. 10(3), 151-160

[8] Atutxa, A., Aguado, R., Gayubo, A.G., Olazar, M., Bilbao, J., 2005. Kinetic description of the catalytic pyrolysis of biomass in a conical spouted bed reactor. Energy Fuels. 19(3), 765-774.

[9] Beck, J.S., Vartuli, J.C., Roth, W.J., Leonowicz, M.E., Kresge, C.T., Schmitt, K.D., Chu, C.T.W., Olson, D.H., Sheppard, E.W., 1992. A new family of mesoporous molecular sieves prepared with liquid crystal templates. J. Am. Chem. Soc. 114(27), 10834-10843.

[10] Bertero, M., Sedran, U., 2016. Immediate catalytic upgrading of soybean shell bio-oil. Energy. 94, 171-179.

[11] Bhatia, S., 1989. Zeolite catalysts: principles and applications. CRC press.

[12] Bradbury, A.G.W., Sakai, Y., Shafizadeh, F., 1979. A kinetic model for pyrolysis of cellulose. J. Appl. Polym. Sci. 23(11), 3271-3280.
[13] Brem, G., Bramer, E.A., 2007. PyRos: a new flash pyrolysis technology for the production of bio-oil from biomass residues. Paper presented at: bio energy outlook. 25-27.

[14] Bridgwater, A.V., 1994. Catalysis in thermal biomass conversion. Appl. Catal., A. 116(1-2), 5-47.

[15] Bridgwater, A.V., 1999. Principles and practice of biomass fast pyrolysis processes for liquids. J. Anal Appl. Pyrolysis. 51(1-2), 322.

[16] Bridgwater, A.V., 2003. Renewable fuels and chemicals by therma processing of biomass. Chem. Eng. J. 91(2-3), 87-102.

[17] Bridgwater, A.V., 2012. Review of fast pyrolysis of biomass and product upgrading. Biomass Bioenergy. 38(0), 68-94.

[18] Bridgwater, A.V., Meier, D., Radlein, D., 1999. An overview of fast pyrolysis of biomass. Org. Geochem. 30(12), 1479-1493

[19] Bridgwater, A.V., Peacocke, G.V.C., 2000. Fast pyrolysis processes for biomass. Renew. Sust. Energy Rev. 4(1), 1-73

[20] Carlson, T.R., Tompsett, G.A., Conner, W.C., Huber, G.W., 2009 Aromatic production from catalytic fast pyrolysis of biomassderived feedstocks. Top. Catal. 52(3), 241.

[21] Carlson, T.R., Vispute, T.P., Huber, G.W., 2008. Green gasoline by catalytic fast pyrolysis of solid biomass derived compounds ChemSusChem. 1(5), 397-400.

[22] Carvalho, W.A., Wallau, M., Schuchardt, U., 1999. Iron and copper immobilised on mesoporous MCM-41 molecular sieves as catalysts for the oxidation of cyclohexane. J. Mol. Catal. A: Chem. 144(1), 9199.

[23] Chang, C.C., Hegedus, L.L., 1979. Surface reactions of NO, CO, and $\mathrm{O}_{2}$ near the stoichiometric point: I. Pt-alumina. J. Catal. 57(3), 361 371 .

[24] Chaudhari, K., Das, T.K., Chandwadkar, A.J., Sivasanker, S., 1999 Mesoporous aluminosilicate of the MCM-41 type: its catalytic activity in $n$-hexane isomerization. J. Catal. 186(1), 81-90.

[25] Ciesla, U., Schüth, F., 1999. Ordered mesoporous materials Microporous Mesoporous Mater. 27(2-3), 131-149.

[26] Corma, A., 1995. Inorganic Solid acids and their use in acidcatalyzed hydrocarbon reactions. Chem. Rev. 95(3), 559-614.

[27] Corma, A., Martínez, A., Martínez-Soria, V., 1997. Hydrogenation of aromatics in diesel fuels on Pt/MCM-41 catalysts. J. Catal. 169(2), 480-489.

[28] Corma, A., Navarro, M.T., Pariente, J.P., 1994. Synthesis of an ultralarge pore titanium silicate isomorphous to MCM-41 and its application as a catalyst for selective oxidation of hydrocarbons. J. Chem. Soc., Chem. Commun. (2), 147-148.

[29] Corma, A., Navarro, M.T., Pérez-Pariente, J., Sánchez, F., 1994 Preparation and properties of Ti-containing MCM-41, in: Weitkamp, H.G.K.H.P.J., Hölderich, W. (Eds.), Studies in Surface Science and Catalysis. Elsevier, 84, 69-75

[30] Czernik, S., Bridgwater, A.V., 2004. Overview of applications of biomass fast pyrolysis oil. Energy Fuels. 18(2), 590-598

[31] Dao, L.H., Haniff, M., Houle, A. and Lamothe, D., 1988. Reactions of model compounds of biomass-pyrolysis oils over ZSM-5 zeolite catalysts. In ACS Symposium Series, American Chemical Society. 376, 328-341.

[32] Dayton, D.C., Carpenter, J.R., Kataria, A., Peters, J.E., Barbee, D. Mante, O.D., Gupta, R., 2015. Design and operation of a pilot-scale catalytic biomass pyrolysis unit. Green Chem. 17(9), 4680-4689.

[33] Di Blasi, C., Branca, C., Galgano, A., 2006. Effects of diammonium phosphate on the yields and composition of products from wood pyrolysis. Ind. Eng. Chem. Res. 46(2), 430-438.

[34] Di Blasi, C., Branca, C., Galgano, A., 2007. Effects of diammonium phosphate on the yields and composition of products from wood pyrolysis. Ind. Eng. Chem. Res. 46(2), 430-438.

[35] Di Blasi, C., Branca, C., Galgano, A., 2008. Thermal and catalytic decomposition of wood impregnated with sulfur- and phosphoruscontaining ammonium salts. Polym. Degrad. Stab. 93(2), 335-346.

[36] Di Blasi, C., Galgano, A., Branca, C., 2009a. Effects of potassium hydroxide impregnation on wood pyrolysis. Energy Fuels. 23(2), 1045-1054. 
[37] Di Blasi, C., Galgano, A., Branca, C., 2009b. Influences of the chemical state of alkaline compounds and the nature of alkali metal on wood pyrolysis. Ind. Eng. Chem. Res. 48(7), 3359-3369.

[38] Ding, L., Rahimi, P., Hawkins, R., Bhatt, S., Shi, Y., 2009. Naphthenic acid removal from heavy oils on alkaline earth-metal oxides and $\mathrm{ZnO}$ catalysts. Appl. Catal., A. 371(1-2), 121-130.

[39] Elliott, D.C., 2007. Historical developments in hydroprocessing bio-oils. Energy Fuels. 21(3), 1792-1815.

[40] Engtrakul, C., Mukarakate, C., Starace, A.K., Magrini, K.A., Rogers, A.K., Yung, M.M., 2016. Effect of ZSM-5 acidity on aromatic product selectivity during upgrading of pine pyrolysis vapors. Catal. Today. 269, 175-181.

[41] Fahmi, R., Bridgwater, A.V., Darvell, L.I., Jones, J.M., Yates, N., Thain, S., Donnison, I.S., 2007. The effect of alkali metals on combustion and pyrolysis of Lolium and Festuca grasses, switchgrass and willow. Fuel. 86(10-11), 1560-1569.

[42] Fermoso, J., Hernando, H., Jana, P., Moreno, I., Přech, J., OchoaHernández, C., Pizarro, P., Coronado, J.M., Čejka, J., Serrano, D.P., 2016. Lamellar and pillared ZSM-5 zeolites modified with MgO and $\mathrm{ZnO}$ for catalytic fast-pyrolysis of eucalyptus woodchips. Catal. Today. 277, 171-181.

[43] Fischer, A., Du, S., Valla, J.A., Bollas, G.M., 2015. The effect of temperature, heating rate, and ZSM-5 catalyst on the product selectivity of the fast pyrolysis of spent coffee grounds. RSC Adv. 5(37), 2925229261

[44] French, R., Czernik, S., 2010. Catalytic pyrolysis of biomass for biofuels production. Fuel Process. Technol. 91(1), 25-32.

[45] Gayubo, A.G., Aguayo, A.T., Atutxa, A., Aguado, R., Bilbao, J., 2004. Transformation of oxygenate components of biomass pyrolysis oil on a HZSM-5 Zeolite. I. Alcohols and phenols. Ind. Eng. Chem. Res. 43(11), 2610-2618.

[46] Gayubo, A.G., Aguayo, A.T., Atutxa, A., Aguado, R., Olazar, M., Bilbao, J., 2004. Transformation of oxygenate components of biomass pyrolysis oil on a HZSM-5 zeolite. II. Aldehydes, ketones, and acids. Ind. Eng. Chem. Res. 43(11), 2619-2626.

[47] Gayubo, A.G., Aguayo, A.T., Atutxa, A., Valle, B., Bilbao, J., 2005. Undesired components in the transformation of biomass pyrolysis oil into hydrocarbons on an HZSM-5 zeolite catalyst. J. Chem. Technol. Biotechnol. 80(11), 1244-1251.

[48] He, N.Y., Bao, S.L., Xu, Q.H., 1997. Synthesis and characterization of FeSiMCM-41 and LaSiMCM-41, in: Hakze Chon, S.K.I., Hakze Chon, U. (Eds.), Young Sun Studies in Surface Science and Catalysis. Elsevier, $105,85-92$.

[49] Henrich, E., Dahmen, N., Raffelt, K., Stahl, R., Weirich, F., 2007. The status of the FZK concept for biomass gasification, $2^{\text {nd }}$. European Summer School on Renewable Motor Fuels, Poland.

[50] Hernando, H., Moreno, I., Fermoso, J., Ochoa-Hernández, C., Pizarro, P., Coronado, J.M., Čejka, J., Serrano, D.P., 2017. Biomass catalytic fast pyrolysis over hierarchical ZSM-5 and Beta zeolites modified with $\mathrm{Mg}$ and $\mathrm{Zn}$ oxides. Biomass Convers. Biorefin. 7(3), 289-304.

[51] Hoff, T.C., Gardner, D.W., Thilakaratne, R., Wang, K., Hansen, T.W., Brown, R.C., Tessonnier, J.P., 2016. Tailoring ZSM-5 zeolites for the fast pyrolysis of biomass to aromatic hydrocarbons. ChemSusChem. 9(12), 1473-1482.

[52] Horne, P.A., Nugranad, N., Williams, P.T., 1995. Catalytic coprocessing of biomass-derived pyrolysis vapours and methanol. J. Anal. Appl. Pyrolysis. 34(1), 87-108.

[53] Horne, P.A., Williams, P.T., 1994. Climate change Energy and the environment Premium quality fuels and chemicals from the fluidised bed pyrolysis of biomass with zeolite catalyst upgrading. Renewable Energy. 5(5-8), 810-812.

[54] Horne, P.A., Williams, P.T., 1995. The effect of zeolite ZSM-5 catalyst deactivation during the upgrading of biomass-derived pyrolysis vapours. J. Anal. Appl. Pyrolysis. 34(1), 65-85.

[55] Horne, P.A., Williams, P.T., 1996. Upgrading of biomass-derived pyrolytic vapours over zeolite ZSM-5 catalyst: effect of catalyst dilution on product yields. Fuel. 75(9), 1043-1050.

[56] Iliopoulou, E.F., Antonakou, E.V., Karakoulia, S.A., Vasalos, I.A., Lappas, A.A., Triantafyllidis, K.S., 2007. Catalytic conversion of biomass pyrolysis products by mesoporous materials: effect of steam stability and acidity of Al-MCM-41 catalysts. Chem. Eng. J. 134(13), 51-57.

[57] Iliopoulou, E.F., Stefanidis, S., Kalogiannis, K., Psarras, A.C., Delimitis, A., Triantafyllidis, K.S., Lappas, A.A., 2014. Pilot-scale validation of Co-ZSM-5 catalyst performance in the catalytic upgrading of biomass pyrolysis vapours. Green Chem. 16(2), 662 674.

[58] Iliopoulou, E.F., Stefanidis, S.D., Kalogiannis, K.G., Delimitis, A. Lappas, A.A., Triantafyllidis, K.S., 2012. Catalytic upgrading of biomass pyrolysis vapors using transition metal-modified ZSM-5 zeolite. Appl. Catal., B. 127, 281-290.

[59] Imran, A., Bramer, E.A., Seshan, K., Brem, G., 2016. Catalytic flash pyrolysis of oil-impregnated-wood and jatropha cake using sodium based catalysts. J. Anal. Appl. Pyrolysis. 117, 236-246.

[60] Imran, A., Bramer, E.A., Seshan, K., Brem, G., 2014. High quality bio-oil from catalytic flash pyrolysis of lignocellulosic biomass over alumina-supported sodium carbonate. Fuel Process. Technol. 127(0), $72-79$

[61] Jae, J., Coolman, R., Mountziaris, T.J., Huber, G.W., 2014. Catalytic fast pyrolysis of lignocellulosic biomass in a process development unit with continual catalyst addition and removal. Chem. Eng. Sci. 108, 33-46.

[62] Jahirul, M., Rasul, M., Chowdhury, A., Ashwath, N., 2012. Biofuels production through biomass pyrolysis-a technological review. Energies. 5(12), 4952-5001

[63] Jensen, A., Dam-Johansen, K., Wójtowicz, M.A., Serio, M.A., 1998 TG-FTIR study of the influence of potassium chloride on wheat straw pyrolysis. Energy Fuels. 12(5), 929-938.

[64] Katikaneni, S.P.R., Adjaye, J.D., Bakhshi, N.N., 1995. Performance of aluminophosphate molecular sieve catalysts for the production of hydrocarbons from wood-derived and vegetable oils. Energy Fuels. 9(6), 1065-1078.

[65] KiOR, I., 2016. KiOR production facilities.

[66] Kirk-Othmer., 2007. Encyclopedia of chemical technology. ISBN 978-0-471-48494-3.

[67] Lappas, A.A., Samolada, M.C., Iatridis, D.K., Voutetakis, S.S., Vasalos, I.A., 2002. Biomass pyrolysis in a circulating fluid bed reactor for the production of fuels and chemicals. Fuel. 81(16), 2087 2095.

[68] Lewandowska, A., Monteverdi, S., Bettahar, M., Ziolek, M., 2002. MCM-41 mesoporous molecular sieves supported nickel-physicochemical properties and catalytic activity in hydrogenation of benzene. J. Molecul. Catal. A: Chem. 188(1-2), 85-95.

[69] Li, B., Lv, W., Zhang, Q., Wang, T., Ma, L., 2014. Pyrolysis anc catalytic upgrading of pine wood in a combination of auger reactor and fixed bed. Fuel. 129, 61-67.

[70] Li, J., Li, X., Zhou, G., Wang, W., Wang, C., Komarneni, S., Wang, Y., 2014. Catalytic fast pyrolysis of biomass with mesoporous ZSM5 zeolites prepared by desilication with $\mathrm{NaOH}$ solutions. Appl. Catal., A. 470, 115-122.

[71] Li, P., Li, D., Yang, H., Wang, X., Chen, H., 2016. Effects of Fe', Zr, and co-modified zeolites and pretreatments on catalytic upgrading of biomass fast pyrolysis vapors. Energy Fuels. 30(4), 3004-3013.

[72] Liang, J., Morgan, H.M., Liu, Y., Shi, A., Lei, H., Mao, H., Bu, Q., 2017. Enhancement of bio-oil yield and selectivity and kinetic study of catalytic pyrolysis of rice straw over transition metal modified ZSM-5 catalyst. J. Anal. Appl. Pyrolysis. 128, 324-334.

[73] Liden, A., Berruti, F., Scott, D., 1988. A kinetic model for the production of liquids from the flash pyrolysis of biomass. Chem. Eng. Commun. 65(1), 207-221.

[74] Lin, Y., Zhang, C., Zhang, M., Zhang, J., 2010. Deoxygenation of bio-oil during pyrolysis of biomass in the presence of $\mathrm{CaO}$ in a fluidized-bed reactor. Energy Fuels. 24(10), 5686-5695.

[75] Lisa, K., Stanton, A.R., Czernik, S., 2012. Production of hydrocarbon fuels from biomass by catalytic fast pyrolysis. Golden, CO: National Renew. Energy Lab. (NREL). 
[76] Lu, Q., Zhang, Z.F., Dong, C.Q., Zhu, X.F., 2010. Catalytic upgrading of biomass fast pyrolysis vapors with nano metal oxides: an analytical Py-GC/MS study. Energies. 3(11), 1805-1820.

[77] Luan, Z., Xu, J., He, H., Klinowski, J., Kevan, L., 1996. Synthesis and spectroscopic characterization of vanadosilicate mesoporous MCM-41 molecular sieves. J. Phys. Chem. 100(50), 19595-19602.

[78] Maggi, R., Delmon, B., 1994. Characterization and upgrading of bio-oils produced by rapid thermal processing. Biomass Bioenergy. 7(1-6), 245249.

[79] Mante, O.D., Agblevor, F.A., Oyama, S.T., McClung, R., 2014. Catalytic pyrolysis with ZSM-5 based additive as co-catalyst to Yzeolite in two reactor configurations. Fuel. 117, 649-659.

[80] Mortensen, P.M., Grunwaldt, J.D., Jensen, P.A., Knudsen, K.G., Jensen, A.D., 2011. A review of catalytic upgrading of bio-oil to engine fuels. Appl. Catal., A. 407(1-2), 1-19.

[81] Mullen, C.A., Boateng, A.A., 2015. Production of aromatic hydrocarbons via catalytic pyrolysis of biomass over Fe-modified HZSM-5 zeolites. ACS Sust. Chem. Eng. 3(7), 1623-1631.

[82] Nesterenko, N.S., Ponomoreva, O.A., Yuschenko, V.V., Ivanova, I.I., Testa, F., Di Renzo, F., Fajula, F., 2003. Dehydrogenation of ethylbenzene and isobutane over Ga-and Fe-containing mesoporous silicas. Appl. Catal., A. 254(2), 261-272.

[83] Nguyen, T.S., Zabeti, M., Lefferts, L., Brem, G., Seshan, K., 2013. Conversion of lignocellulosic biomass to green fuel oil over sodium based catalysts. Bioresour. Technol. 142, 353-360.

[84] Noreña-Franco, L., Hernandez-Perez, I., Aguilar-Pliego, J., MaubertFranco, A., 2002. Selective hydroxylation of phenol employing $\mathrm{Cu}-$ MCM-41 catalysts. Catal. Today. 75(1-4), 189-195

[85] Nowakowski, D.J., Jones, J.M., Brydson, R.M.D., Ross, A.B., 2007. Potassium catalysis in the pyrolysis behaviour of short rotation willow coppice. Fuel. 86(15), 2389-2402.

[86] Oasmaa, A., Czernik, S., 1999. Fuel oil quality of biomass pyrolysis oils state of the art for the end users. Energy Fuels. 13(4), 914-921.

[87] Oasmaa, A., Kuoppala, E., 2003. Fast pyrolysis of forestry residue. 3. Storage stability of liquid fuel. Energy Fuels. 17(4), 1075-1084.

[88] Occelli, M.L., Biz, S., Auroux, A., 1999. Effects of isomorphous substitution of $\mathrm{Si}$ with $\mathrm{Ti}$ and $\mathrm{Zr}$ in mesoporous silicates with the MCM41 structure. Appl. Catal., A. 183(2), 231-239.

[89] Olazar, M., Aguado, R., Bilbao, J., Barona, A., 2000. Pyrolysis of sawdust in a conical spouted-bed reactor with a HZSM-5 catalyst. AIChE J. 46(5), 1025-1033.

[90] Paasikallio, V., Agblevor, F., Oasmaa, A., Lehto, J., Lehtonen, J., 2013. Catalytic pyrolysis of forest thinnings with ZSM-5 catalysts: effect of reaction temperature on bio-oil physical properties and chemical composition. Energy Fuels. 27(12), 7587-7601.

[91] Parvulescu, V., Su, B.L., 2001. Iron, cobalt or nickel substituted MCM41 molecular sieves for oxidation of hydrocarbons. Catal. Today. 69(14), 315-322.

[92] Pattiya, A., Titiloye, J.O., Bridgwater, A.V., 2010. Evaluation of catalytic pyrolysis of cassava rhizome by principal component analysis. Fuel. 89(1), 244-253.

[93] Pattiya, A., Titiloye, J.O., Bridgwater, A.V., 2008. Fast pyrolysis of cassava rhizome in the presence of catalysts. J. Anal. Appl. Pyrolysis. 81(1), 72-79

[94] Piskorz, J., Scott, D.S., Radlein, D., 1988. Composition of oils obtained by fast pyrolysis of different woods, in: pyrolysis oils from Biomass. Am. Chem. Soc. 376, 167-178.

[95] Pütün, E., 2010. Catalytic pyrolysis of biomass: effects of pyrolysis temperature, sweeping gas flow rate and $\mathrm{MgO}$ catalyst. Energy. 35(7), 2761-2766.

[96] Pütün, E., Uzun, B.B., Pütün, A.E., 2009. Rapid pyrolysis of olive residue. 2. Effect of catalytic upgrading of pyrolysis vapors in a twostage fixed-bed reactor. Energy Fuels. 23(4), 2248-2258.

[97] Raveendran, K., Ganesh, A., Khilar, K.C., 1995. Influence of mineral matter on biomass pyrolysis characteristics. Fuel. 74(12), 1812-1822.

[98] Sadeghbeigi, R., 2000. Chapter 3-FCC catalysts, Second Edition, in: Sadeghbeigi, R. (Ed.), Fluid Catalytic Cracking Handbook. Gulf Professional Publishing. Houston, 84-124.

[99] Saijonkari-Pahkala, K., 2001. Non-wood plants as raw material for pulp and paper. Finland.
[100] Samolada, M.C., Papafotica, A., Vasalos, I.A., 2000. Catalyst evaluation for catalytic biomass pyrolysis. Energy Fuels. 14(6), 1161-1167.

[101] Savidha, R., Pandurangan, A., Palanichamy, M., Murugesan, V., 2004. A comparative study on the catalytic activity of $\mathrm{Zn}$ and $\mathrm{Fe}$ containing Al-MCM-41 molecular sieves on t-butylation of phenol. J. Mol. Catal. A: Chem. 211(1-2), 165-177.

[102] Scholze, B., Hanser, C., Meier, D., 2001. Characterization of the water-insoluble fraction from fast pyrolysis liquids (pyrolytic lignin): part II. GPC, carbonyl goups, and ${ }^{13}$ C-NMR. J. Anal. Appl. Pyrolysis. 58-59, 387-400.

[103] Shadangi, K.P., Mohanty, K., 2014a. Comparison of yield and fuel properties of thermal and catalytic Mahua seed pyrolytic oil. Fuel. $117,372-380$.

[104] Shadangi, K.P., Mohanty, K., 2014b. Thermal and catalytic pyrolysis of Karanja seed to produce liquid fuel. Fuel. 115, 434-442

[105] Stefanidis, S.D., Karakoulia, S.A., Kalogiannis, K.G., Iliopoulou, E.F., Delimitis, A., Yiannoulakis, H., Zampetakis, T., Lappas, A.A., Triantafyllidis, K.S., 2016. Natural magnesium oxide (MgO) catalysts: a cost-effective sustainable alternative to acid zeolites for the in situ upgrading of biomass fast pyrolysis oil. Appl. Catal., B. $196,155-173$

[106] Stephanidis, S., Nitsos, C., Kalogiannis, K., Iliopoulou, E.F., Lappas, A.A., Triantafyllidis, K.S., 2011. Catalytic upgrading of lignocellulosic biomass pyrolysis vapours: effect of hydrothermal pre-treatment of biomass. Catal. Today. 167(1), 37-45.

[107] Sturzl, R., 1997. The commercial co-firing of RTP bio-oil at the Manitowoc Public Utilities power generation station.

[108] Sun, L., Zhang, X., Chen, L., Zhao, B., Yang, S., Xie, X., 2016. Comparision of catalytic fast pyrolysis of biomass to aromatic hydrocarbons over ZSM-5 and Fe/ZSM-5 catalysts. J. Anal. Appl. Pyrolysis. 121, 342-346.

[109] Takeguchi, T., Kim, J.B., Kang, M., Inui, T., Cheuh, W.T., Haller, G.L., 1998. Synthesis and characterization of alkali-free, Gasubstituted MCM-41 and its performance for n-hexane conversion. J. Catal. 175(1), 1-6.

[110] Taralas, G., Kontominas, M.G., 2004. Kinetic modelling of VOC catalytic steam pyrolysis for tar abatement phenomena in gasification/pyrolysis technologies. Fuel. 83(9), 1235-1245.

[111] Thangalazhy-Gopakumar, S., Adhikari, S., Chattanathan, S.A. Gupta, R.B., 2012. Catalytic pyrolysis of green algae for hydrocarbon production using $\mathrm{H}^{+} \mathrm{ZSM}-5$ catalyst. Bioresour. Technol. 118, 150-157.

[112] Twaiq, F.A., Mohamed, A.R., Bhatia, S., 2003. Liquid hydrocarbon fuels from palm oil by catalytic cracking over aluminosilicate mesoporous catalysts with various $\mathrm{Si} / \mathrm{Al}$ ratios. Microporous Mesoporous Mater. 64(1-3), 95-107.

[113] Van de Beld, B., Holle, E., Florijn, J., 2013. The use of pyrolysis oi. and pyrolysis oil derived fuels in diesel engines for CHP applications. Appl. Energy. 102, 190-197.

[114] Veses, A., Aznar, M., Martínez, I., Martínez, J.D., López, J.M., Navarro, M.V., Callén, M.S., Murillo, R., García, T., 2014. Catalytic pyrolysis of wood biomass in an auger reactor using calcium-based catalysts. Bioresour. Technol. 162, 250-258.

[115] Wang, J., Zhang, M., Chen, M., Min, F., Zhang, S., Ren, Z., Yan, Y., 2006. Catalytic effects of six inorganic compounds on pyrolysis of three kinds of biomass. Thermochim. Acta. 444(1), 110-114.

[116] Wang, Z., Wang, F., Cao, J., Wang, J., 2010. Pyrolysis of pine wood in a slowly heating fixed-bed reactor: potassium carbonate versus calcium hydroxide as a catalyst. Fuel Process. Technol. 91(8), 942 950.

[117] Watson, B.A., Klein, M.T., Harding, R.H., 1997. Catalytic cracking of alkylbenzenes: modeling the reaction pathways and mechanisms. Appl. Catal., A. 160(1), 13-39.

[118] White, J.E., Catallo, W.J., Legendre, B.L., 2011. Biomass pyrolysis kinetics: a comparative critical review with relevant agricultural residue case studies. J. Anal. Appl. Pyrolysis. 91(1), 1-33.

[119] Whitmore, F.C., 1934. Mechanism of the polymerization of olefins by acid catalysts. Ind. Eng. Chem. 26(1), 94-95. 
[120] Williams, P.T., Horne, P.A., 1995a. Analysis of aromatic hydrocarbons in pyrolytic oil derived from biomass. J. Anal. Appl. Pyrolysis. 31, 1537.

[121] Williams, P.T., Horne, P.A., 1994. Characterisation of oils from the fluidised bed pyrolysis of biomass with zeolite catalyst upgrading. Biomass Bioenergy. 7(1-6), 223-236.

[122] Williams, P.T., Horne, P.A., 1995b. The influence of catalyst type on the composition of upgraded biomass pyrolysis oils. J. Anal. Appl. Pyrolysis. 31, 39-61.

[123] Williams, P.T., Nugranad, N., 2000. Comparison of products from the pyrolysis and catalytic pyrolysis of rice husks. Energy. 25(6), 493-513.

[124] Wojciechowski, B.W., Corma, A., 1986. Catalytic cracking: catalysts, chemistry, and kinetics.

[125] Wu, Q., Hu, X., Yue, P.L., Zhao, X.S., Lu, G.Q., 2001. Copper/MCM41 as catalyst for the wet oxidation of phenol. Appl. Catal., B. 32(3), $151-156$.

[126] Xiang, Z., Liang, J., Morgan, H.M., Liu, Y., Mao, H., Bu, Q., 2018. Thermal behavior and kinetic study for co-pyrolysis of lignocellulosic biomass with polyethylene over Cobalt modified ZSM-5 catalyst by thermogravimetric analysis. Bioresour. Technol. 247, 804-811.

[127] Yaman, S., 2004. Pyrolysis of biomass to produce fuels and chemical feedstocks. Energy Convers. Manage. 45(5), 651-671.
[128] Yildiz, G., Lathouwers, T., Toraman, H.E., van Geem, K.M., Marin, G.B., Ronsse, F., van Duren, R., Kersten, S.R.A., Prins, W., 2014. Catalytic fast pyrolysis of pine wood: effect of successive catalyst regeneration. Energy Fuels. 28(7), 4560-4572.

[129] Yildiz, G., Ronsse, F., Vercruysse, J., Daels, J., Toraman, H.E., van Geem, K.M., Marin, G.B., van Duren, R., Prins, W., 2016. In situ performance of various metal doped catalysts in micro-pyrolysis and continuous fast pyrolysis. Fuel Process. Technol. 144, 312-322.

[130] Zhang, H., Xiao, R., Huang, H., Xiao, G., 2009. Comparison of noncatalytic and catalytic fast pyrolysis of corncob in a fluidized bed reactor. Bioresour. Technol. 100(3), 1428-1434.

[131] Zhang, H., Xiao, R., Wang, D., Zhong, Z., Song, M., Pan, Q., He, G., 2009. Catalytic fast pyrolysis of biomass in a fluidized bed with fresh and spent fluidized catalytic cracking (FCC) catalysts. Energy Fuels. 23(12), 6199-6206.

[132] Zhang, H., Zheng, J., Xiao, R., Jia, Y., Shen, D., Jin, B., Xiao, G., 2014. Study on pyrolysis of pine sawdust with solid base and acid mixed catalysts by thermogravimetry-fourier transform infrared spectroscopy and pyrolysis-gas chromatography/mass spectrometry. Energy Fuels. 28(7), 4294-4299. 